\title{
Integrin-Mediated Dendrite Branch Maintenance Requires Abelson (Abl) Family Kinases
}

\author{
Eva Marie Yang Moresco, ${ }^{1}$ Stephanie Donaldson, ${ }^{2}$ Anne Williamson, ${ }^{3}$ and Anthony J. Koleske ${ }^{4}$ \\ ${ }^{1}$ Department of Genetics, ${ }^{2}$ Department of Laboratory Medicine, ${ }^{3}$ Department of Neurosurgery, and ${ }^{4}$ Department of Molecular Biophysics and Biochemistry, \\ Department of Neurobiology, and Interdepartmental Neuroscience Program, Yale University School of Medicine, New Haven, Connecticut 06520
}

Dendrite arbor structure is a critical determinant of nervous system function that must be actively maintained throughout life, but the signaling pathways that regulate dendrite maintenance are essentially unknown. We report that the Abelson (Abl) and Abl-related gene (Arg) nonreceptor tyrosine kinases are required for maintenance of cortical dendrites in the mouse brain. $\mathrm{arg}^{-1-} \mathrm{cortical}^{\mathrm{B}} \mathrm{dendrites}$ initially develop normally and are indistinguishable from wild-type dendrites at postnatal day 21. Dendrite branches are not efficiently maintained in $\mathrm{arg}^{-/-}$neurons, leading to a reduction in dendrite arbor size by early adulthood. More severe dendrite loss is observed in $a b l^{-/-} \mathrm{arg}^{-/-}$neurons. Elevation of Arg kinase activity in primary cortical neurons promotes axon and dendrite branching. Activation of integrin receptors by adhesion to laminin-1 or Semaphorin 7A also promotes neurite branching in cortical neurons, but this response is absent in $\mathrm{arg}^{-/-}$neurons because of the reduced dynamic behavior of mutant neurite branches. These data suggest that integrin signaling through $\mathrm{Abl}$ and Arg support cortical dendrite branch maintenance by promoting dendrite branch dynamics in response to adhesive cues.

Key words: dendrite maintenance; cortex; Abl; Arg; integrin; Semaphorin 7A

\section{Introduction}

Dendrite arbor size and branching pattern establish the blueprint for the synaptic connections of a neuron, thereby determining its ability to receive inputs and integrate into neural networks. Postmortem studies of human brain tissue indicate that neurological disorders, including autism, mental retardation, and schizophrenia, are associated with defects in dendritic structure (Huttenlocher, 1974; Purpura, 1975; Kaufmann and Moser, 2000; Broadbelt et al., 2002; Jones, 2004). Reductions or restructuring of dendrites and dendritic spines likely perturb the synaptic connectivity of neuronal circuits, impairing the information-processing capability of the brain. In some conditions, symptoms do not appear until late in development, after dendrite structure is already established, suggesting that dendrites deteriorate in these diseases, and that maintenance of dendritic structure is essential to sustaining normal brain function (Zoghbi, 2003). A growing number of molecules regulating dendrite arbor development have been described previously (Whitford et al., 2002), but

\footnotetext{
Received Feb. 19, 2005; revised May 16, 2005; accepted May 17, 2005.

This work was supported by United States Public Health Service Research Grant NS39475 (A.J.K.) and the Kavli Institute for Neuroscience at Yale University. E.M.Y.M. was supported by a National Science Foundation Predoctoral Award. A.J.K. is a National Alliance for Research on Schizophrenia and Depression Young Investigator and a Scholar of the Leukemia and Lymphoma Society. We are grateful to Xianyun Ye for expert technical assistance, Maithreyi Krishnaswami for purified recombinant Abl and advice on F-actin-binding assays, Trevor Williams for use of the blastocyst injection facility, Jeroen Pasterkamp and Alex Kolodkin for Sema7A reagents and advice, and members of the Koleske laboratory, Charles Greer, Antony Jose, Michael Koelle, Lynn Selemon, Elke Stein, and Steve Strittmatter for helpful discussions.

Correspondence should be addressed to Anthony J. Koleske, Yale University School of Medicine, Molecular Biophysics and Biochemistry, P.0. Box 208024, 333 Cedar Street, New Haven, CT 06520-8024. E-mail: anthony.koleske@yale.edu.

DOl:10.1523/JNEUROSCI.1432-05.2005

Copyright $\odot 2005$ Society for Neuroscience $\quad$ 0270-6474/05/256105-14\$15.00/0
}

whether and how these molecules also control dendrite maintenance is unclear.

Abelson (Abl) family nonreceptor tyrosine kinases, which include vertebrate Abl and Abl-related gene (Arg) proteins, help translate information from cell surface receptors into changes in cytoskeletal structure and cell morphology in non-neuronal cells (Woodring et al., 2003; Hernandez et al., 2004b). The effects on cell structure are mediated in part through Abl- or Arg-mediated phosphorylation of cytoskeletal regulatory proteins, including the Rho inhibitor p190RhoGAP (Hernandez et al., 2004a) and the Ras/Rac activator Sos-1 (Sini et al., 2004). Abl family proteins also have C-terminal extensions containing binding sites for actin and microtubules, which can be used to directly control cytoskeletal structure (McWhirter and Wang, 1993; Van Etten et al., 1994; Wang et al., 2001; Miller et al., 2004) (M. Krishnaswami and A. J. Koleske, unpublished observations). Thus, Abl and Arg use kinase-dependent and kinase-independent mechanisms to mediate changes in cytoskeletal structure.

$\mathrm{Abl}$ and Arg are abundantly expressed in metazoan nervous systems, making them good candidates for regulating the neuronal cytoskeleton in response to morphogenetic cues (Moresco and Koleske, 2003). In flies, Drosophila Abl is expressed in axons of the developing nervous system, where it is required for midline axon and motor neuron axon guidance (Gertler et al., 1989; Elkins et al., 1990; Giniger, 1998; Wills et al., 1999a,b). In addition, several reports have shown that Abl can influence neuronal morphology in cultured neurons. These studies demonstrate that Abl promotes neurite growth, and that reducing Abl function inhibits growth (Zukerberg et al., 2000; Woodring et al., 2002; Jones et al., 2004). However, it is unclear whether and how Abl and Arg regulate neuronal morphogenesis in the intact vertebrate brain. 
We analyzed the structure of cortical neurons in immature and adult mice lacking Abl and/or Arg and found that dendrite arbor maintenance is deficient in these mutants. Using primary cortical neurons, we show that Arg promotes axon and dendrite branching in vitro, and that Arg is required for integrin-mediated neurite branching after adhesion to the extracellular matrix (ECM) protein laminin-1 (laminin) or to the guidance molecule Semaphorin 7A (Sema7A). Our data strongly suggest that reduced responsiveness to adhesive cues compromises cortical dendrite branch maintenance in Abl- and/or Arg-deficient neurons.

\section{Materials and Methods}

Construction of $\mathrm{abl}^{\text {flox }}$ mice. Genomic clones containing the abl-coding sequence were cloned from the $129 / \mathrm{SvJ}$ mouse liver genomic library and mapped and sequenced using $25 \mathrm{bp}$ oligonucleotides corresponding to the mouse $a b l \mathrm{cDNA}$. A $11 \mathrm{~kb}$ Asp718-XbaI $a b l$ genomic fragment was the starting point for construction. A loxP site flanked by an EcoRI site was cloned into the unique PacI site just upstream of $a b l$ exon 5 , and a loxPphosphoglycerate kinase (PGK)-neo ${ }^{\mathrm{R}}$-loxP cassette was cloned into the unique SnaBI site $1.7 \mathrm{~kb}$ downstream of $a b l$ exon 5. A PGK-thymidine kinase cassette was ligated to the XbaI end of the construct. This construct (pTK342) was electroporated into J1 embryonic stem (ES) cells, and clones were selected in G418 and ganciclovir. XbaI-digested genomic DNA was probed with a $1.2 \mathrm{~kb} \mathrm{NdeI-EcoRI} \mathrm{probe} \mathrm{to} \mathrm{identify} \mathrm{correctly}$ targeted clones (11 of 387). Correctly targeted ES clones were expanded and electroporated with a cAMP response element (Cre)-expression construct to eliminate the loxP-PGK-neo ${ }^{\mathrm{R}}$-loxP cassette. Clones that regained sensitivity to G418 were examined by Southern blot analysis for loss of the loxP-PGK-neo ${ }^{\mathrm{R}}$-loxP cassette. $a b^{\text {flox }}$ mice and their derivatives were generated as described previously (Li et al., 1992).

Strategy to eliminate Abl and Arg function in developing neurons. We crossed the $a b f^{f l o x}$ allele into the $\mathrm{arg}^{-1-}$ background and inactivated the $a b f^{f l o x}$ allele using nestin-Cre transgenic mice (Isaka et al., 1999). Southern blot analysis confirmed that the abflox allele was recombined efficiently in the brains of the abflox/+ nestin-Cre ${ }^{+}$mice but not in their spleens (supplemental Fig. $1 C$, available at www.jneurosci.org as supplemental material). Only $35 \%$ of the expected Mendelian numbers of abflox/flox $\mathrm{arg}^{-1-}$ nestin-Cre $e^{+}$mice were born $(n=302$ progeny from intercrosses of $a b f^{\text {flox/+ }} \mathrm{arg}^{+/-}$nestin-Cre ${ }^{+}$males and females). Those that were born survived well into adulthood.

Reverse transcriptase-PCR. Total RNA was isolated from mouse tissues using Trizol reagent (Invitrogen, Grand Island, NY), copied by reverse transcriptase, and amplified by PCR using the following primers: $5^{\prime}$ GCCCTGGCCAGAGATCCATC-3' and 5'-TCCCTCAGGTAGTCCA GCAGG-3'.

Immunoblotting. Tissue samples were disrupted in radioimmunoprecipitation assay buffer containing protease inhibitors on ice (Koleske et al., 1998), and the protein concentration was determined using the bicinchronic acid assay (Pierce Biotechnology, Rockford, IL). Extracts were separated on $8 \%$ SDS-PAGE, blotted to nitrocellulose membrane, and probed with antibodies specific to the Abl kinase domain (PharMingen, San Diego, CA), the Abl C terminus (Santa Cruz Biotechnology, Santa Cruz, CA), or heat shock protein 70 (a gift from Dr. Peter Murray, St. Jude Children's Research Hospital, Memphis, TN).

Kinase and F-actin-binding assays. His-tagged $\mathrm{Abl}$ and $\mathrm{Abl} \Delta$ kin were produced in Hi5 insect cells and purified on nickel-nitrolotriacetic acid beads as described previously (Wang et al., 2001). Kinase assays (Tanis et al., 2003) and F-actin-binding assays (Wang et al., 2001) were performed as described previously. F-actin-binding experiments were repeated with F-actin concentrations from 0 to $27 \mu \mathrm{M}$ to determine $K_{\mathrm{d}}$ for F-actin binding as described previously (Wang et al., 2001; Miller et al., 2004).

Bromodeoxyuridine labeling. Pregnant female mice were injected with bromodeoxyuridine (BrdU; $100 \mu \mathrm{g} / \mathrm{g}$, i.p.) on days indicated and were allowed to carry embryos to term. Pups were genotyped between postnatal day 10 (P10) and P14 as usual. Controls were always gendermatched littermates. Animals used for experiments at P21 were treated as described for other immunohistochemistry. For quantitation of BrdU- labeled cells, images at $10 \times$ magnification of the cortex in coronal sections were captured as for cortical layer cell density estimation. For each section, a $650-\mu \mathrm{m}$-wide strip was drawn through the thickness of the cortex in each hemisphere. This strip was divided into rectangles $150 \mu \mathrm{m}$ high (by $650 \mu \mathrm{m}$ wide), stacked one on top of the other, through the entire thickness of the cortex. BrdU-labeled cells were counted manually using Openlab software for each rectangle and graphed versus the distance from the pial surface (expressed in $150 \mu \mathrm{m}$ increments). Cortical thickness varied little from section to section. Thickness was between 750 and $900 \mu \mathrm{m}$ so that the last rectangle was not always the full $150 \mu \mathrm{m}$ in height; cells were counted as part of this last rectangle as usual. Sections were stained with $\alpha$-BrdU monoclonal antibody (mAb) (1:100; Becton Dickinson, San Jose, CA) as described here.

Immunohistochemistry. Mice were deeply anesthetized and transcardially perfused with ice-cold PBS followed by $4 \%$ paraformaldehyde/PBS. Brains were dissected and postfixed overnight in $4 \%$ paraformaldehyde/ PBS at $4^{\circ} \mathrm{C}$. After rinsing in PBS for at least $1 \mathrm{~h}$, brains were bisected sagittally, and $50-\mu \mathrm{m}$-thick sagittal sections [for $\alpha$-neuronal-specific nuclear protein $(\alpha-\mathrm{NeuN})$ staining] were cut with a vibratome and collected into PBS. Whole brains were sectioned coronally (50 $\mu \mathrm{m}$ thick) for $\alpha$-BrdU and $\alpha$-L1 staining. For $\alpha$-NeuN staining, every eighth (6- to 8 -week-old mice) or ninth (P21-P23 mice) sagittal section from each half-brain was selected for staining. For $\alpha$-BrdU and $\alpha$-L1 staining, matched coronal sections from the forebrain, midbrain, and hindbrain were selected for staining. Primary antibodies were $\alpha$-NeuN mAb (1 $\mu \mathrm{g} / \mathrm{ml}$; Chemicon, Temecula, CA), $\alpha$-L1 mAb $(2.1 \mu \mathrm{g} / \mathrm{ml}$ ASCS4 concentrate; developed by Paul H. Patterson; Developmental Studies Hybridoma Bank, University of Iowa, Iowa City, IA), $\alpha$-BrdU mAb (1:100; Becton Dickinson), and $\alpha$-S-100 $\beta$ (1:1000; Sigma, St. Louis, MO).

Sections were blocked for endogenous peroxidase activity with $3 \%$ $\mathrm{H}_{2} \mathrm{O}_{2} / \mathrm{PBS}$ for $15 \mathrm{~min}$ at room temperature, rinsed in PBS plus $0.3 \%$ Triton X-100 (PBS/T), and then blocked for $30 \mathrm{~min}$ in $2 \% \mathrm{BSA}$ in PBS/T at room temperature. Sections were incubated for $1 \mathrm{~h}$ at room temperature or overnight at $4^{\circ} \mathrm{C}$ in primary antibody, washed in PBS/T, and incubated in goat $\alpha$-mouse-biotin or goat $\alpha$-rabbit-biotin $(1 \mu \mathrm{g} / \mathrm{ml}$; Jackson ImmunoResearch, West Grove, PA) for $1 \mathrm{~h}$ at room temperature. After washing in PBS/T, sections were incubated in avidin-biotinperoxidase complex (Vectastain Elite ABC Reagent, prepared as directed; Vector Laboratories, Burlingame, CA) for $30 \mathrm{~min}$ and rinsed in PBS/T and then PBS, followed by diaminobenzidine tetrahydrochloride visualization (Sigma). Sections were rinsed in PBS, mounted on slides, dried, cleared, and mounted on coverslips with Permount (Fisher Scientific, Pittsburgh, PA). Staining for $\alpha$-BrdU was identical, except that, after blocking endogenous peroxidase, sections were treated with $2 \mathrm{~N} \mathrm{HCl}$ for $30 \mathrm{~min}$ at room temperature. Staining for $\alpha$-L1 was identical, except that, before beginning staining, sections were boiled in $0.1 \mathrm{M}$ sodium citrate, $\mathrm{pH} 4.5$, for $15 \mathrm{~min}$ followed by rinsing three times for $5 \mathrm{~min}$ each in PBS.

Estimation of cortical neuron number, cortical volume, and cortical glial cell density. Because of the slight variability in the timing of brain development between litters, gender-matched littermate controls were always used for these experiments. Each control mouse contained at least one wild-type $a b l$ allele and one wild-type arg allele. Stereological analysis by an investigator blind to genotypes was performed on NeuN-stained sections using the Optical Fractionator probe in the StereoInvestigator software (MicroBrightField, Colchester, VT). In each section, the cortical region (excluding layer 1 because of cell sparseness) was traced carefully and used as the contour for Optical Fractionator. The following parameters were set for cell counts: counting frame size, $40.00 \times 24.04 \mu \mathrm{m}$; scan grid size, $1300 \times 1000 \mu \mathrm{m}$; distance from section top to threedimensional counting frame, $5 \mu \mathrm{m}$. Between 239 and 454 cells were counted for each set of sections from each animal, resulting in a Gundersen coefficient of error $\leq 0.06(m=1)$. Total cortical cell number and cortical volume estimates were used to calculate cell density (cells per unit volume).

For cortical layer, cell-density estimates, images of the visual cortex in NeuN-stained sections under $10 \times$ magnification were captured using a Nikon TE2000-S inverted light microscope connected to a Retiga-cooled monochrome digital camera (Qimaging, Burnaby, British Columbia, Canada) and Openlab software (Improvision, Lexington, MA). The vi- 
sual cortex was identified based on positions in the study by Franklin and Paxinos (1997). Two 200- $\mu \mathrm{m}$-wide strips were drawn in the visual cortex of one sagittal section from each brain. Layers were delineated in each strip based on cell density and cell size and were easily identified in mutants and controls. NeuN-stained cells were counted manually for each layer in the $200-\mu \mathrm{m}$-wide strip. Cell number and layer thickness measurements were made using Openlab software and were used to calculate cell density (cells per unit area).

To estimate cortical glial cell density, stereological analysis was performed on S-100 $\beta$-stained sections using the Optical Fractionator probe in the StereoInvestigator software. In each section, the cortical region was traced carefully and used as the contour for Optical Fractionator. The following parameters were set for cell counts: counting frame size, $65.00 \times 50.00 \mu \mathrm{m}$; scan grid size, $1000 \times 1000 \mu \mathrm{m}$; distance from the top section to the three-dimensional counting frame, $5 \mu \mathrm{m}$. Approximately 100 cells were counted for each set of sections from each animal. Glial cell number and cortical volume estimates were used to calculate cell density (cells per unit volume).

Golgi staining. Staining was performed following the protocol of Gibb and Kolb (1998). Tissue impregnation with the Golgi-Cox solution was for 3-5 d. Vibratome sections were made at $150 \mu \mathrm{m}$ thickness.

DiI anterograde labeling. To label the trajectories of callosal axons innervating the cortex, one or two crystals of DiI (Molecular Probes, Eugene, OR) were placed into the center of the corpus callosum in coronal slabs $(\sim 1-1.3 \mathrm{~mm}$ thick) from brains that were perfusion-fixed and postfixed with $4 \%$ paraformaldehyde/PBS as described above. Brain slabs were then incubated in $4 \%$ paraformaldehyde/PBS in the dark at $37^{\circ} \mathrm{C}$ for 1 month and then sectioned coronally with a vibratome at $30 \mu \mathrm{m}$. Sections were mounted on slides in 4\% paraformaldehyde/PBS. Epifluorescence was observed and imaged with a Nikon (Tokyo, Japan) TE2000-Sinverted light microscope connected to a Retiga-cooled monochrome digital camera and Openlab software.

For quantitation of cortical afferent targeting, $60 \mu \mathrm{m}$ cortical sections containing DiI-labeled axons were incubated in ice-cold diaminobenzidine ( $2 \mathrm{mg} / \mathrm{ml}$ in $50 \mathrm{~mm}$ Tris, $\mathrm{pH} 7.5)$ and photoconverted to dark precipitate using fluorescent illumination in the red channel, with changing of the solution every $15 \mathrm{~min}$. A strip template was drawn over a section of cortex and divided equally into five bins of equal size with bin 1 nearest the pial surface and bin 5 nearest the corpus callosum. Axons within each bin were traced and quantified using Neurolucida software.

Morphometric analysis of neurons. Individual neurons labeled by Golgi staining were traced under $100 \times$ magnification using a light microscope fitted with a Z-drive and reconstructed using Neurolucida software. Sholl analysis, total dendrite length, mean dendrite length, numbers of branchpoints (nodes), average segment length, and numbers of segments were calculated using NeuroExplorer software (MicroBrightField). In Sholl analysis, concentric three-dimensional shells of increasing radius are centered on the cell body of the neuron; the number of intersections of the dendrite arbor with a given shell is plotted versus the shell radius. Total dendrite length and numbers of branchpoints were used to calculate branchpoint density. All cells were traced with an experimenter blinded to the genotypes.

Fluorescent images of cultured cortical neurons expressing Arg or Arg mutants and yellow fluorescent protein (YFP) were captured at $20 \times$ magnification with a Nikon TE2000-S-inverted light microscope connected to a Retiga-cooled monochrome digital camera and Openlab software. For experiments examining integrin-dependent neurite outgrowth of wild-type or $\mathrm{arg}^{-1-}$ neurons, cells were imaged in phase contrast. To minimize effects of cell-cell interactions on dendrite morphogenesis, only neurons that were not in contact with other cells were selected for analysis. Images were imported into Neurolucida, and neurons were traced, reconstructed, and analyzed as described above. For each transfection condition, between four and eight independent cultures (10-65 individual neurons from each culture) were analyzed. For each culture condition to examine integrin-dependent neurite outgrowth, one to four independent cultures each of wild-type or $\mathrm{arg}^{-1-}$ neurons ( $\sim 30$ individual neurons from each culture) were analyzed. All cells were imaged and traced with an experimenter blinded to transfection condition, culture condition, and genotype.
Primary neuron cultures, transfections, and immunostaining. Cortical cultures were prepared from embryonic day 15 (E15) mouse embryos. Cortices were dissected in ice-cold HBSS (Invitrogen) supplemented with $25 \mathrm{~mm}$ HEPES and $0.5 \%$ glucose, minced, and digested in $0.3 \mathrm{U} / \mathrm{ml}$ papain (Worthington, Lakewood, NJ), 0.1\% dispase (Roche, Indianapolis, IN), and $0.01 \%$ DNaseI (Sigma) in HBSS plus HEPES/glucose at $37^{\circ} \mathrm{C}$ (twice for $7 \mathrm{~min}$ ). Tissue was triturated 20 times with a glass Pasteur pipette with a fire-polished tip. Dissociated cells were resuspended in Neurobasal media supplemented with B27, 5\% fetal calf serum, $1 \mathrm{~mm}$ sodium pyruvate, and $2 \mathrm{~mm}$ L-glutamine (all from Invitrogen) and plated at 17,500 cells/well on glass coverslips in 24-well plates. Coverslips were acid washed and coated with poly-L-ornithine (ornithine; Sigma) for $1 \mathrm{~h}$ at room temperature, followed by $4 \mu \mathrm{g} / \mathrm{ml}$ mouse laminin-1 (Invitrogen, Carlsbad, CA) in PBS overnight at $37^{\circ} \mathrm{C}$.

Cells were transfected at $2 \mathrm{~d}$ in vitro (DIV) by a calcium phosphate transfection procedure as described previously (Threadgill et al., 1997). For each well, $3 \mu \mathrm{g}$ of experimental plasmid and $1 \mu \mathrm{g}$ of pEYFP-N1 plasmid (Clontech, Palo Alto, CA) was added. After $1 \mathrm{~h}$ of incubation at $37^{\circ} \mathrm{C}$, each well was washed with PBS to remove precipitate, and warmed original culture media was replaced. Cells were fixed at 4 DIV in $4 \%$ paraformaldehyde/4\% sucrose in PBS for $15 \mathrm{~min}$ at room temperature. Coverslips were mounted on slides with Aquamount (Lerner Laboratories, Pittsburgh, PA).

For transfection of Arg-YFP into cultured neurons, $4 \mu \mathrm{g}$ of pX1-ArgYFP plasmid (Miller et al., 2004) was added to each well. Control YFP transfections contained $1 \mu \mathrm{g}$ of pEYFP-N1 and $3 \mu \mathrm{g}$ of pX1 vector added to each well. Cells were fixed at indicated times.

For integrin-dependent neurite outgrowth experiments, wild-type or $\mathrm{arg}^{-1-}$ neurons were prepared in parallel, as described above, and plated on coverslips coated with $0.01 \%$ poly-L-ornithine for $1 \mathrm{~h}$ at room temperature, followed by $4 \mu \mathrm{g} / \mathrm{ml}$ mouse laminin- 1 in PBS, PBS alone, 5 or $10 \mu \mathrm{g} / \mathrm{ml}$ mouse Netrin-1 (R \& D Systems, Minneapolis, MN), or human embryonic kidney 293 cell-conditioned media from transiently or stably transfected cells expressing alkaline phosphatase (AP)-tag5 (GenHunter, Nashville, TN) or AP-Sema7A overnight at $37^{\circ} \mathrm{C}$. Concentrations of APtag5 and AP-Sema7A were determined by colorimetric (4nitrophenylphosphate) alkaline phosphatase activity assay using human placental alkaline phosphatase (Sigma) as a standard. Drugs [echistatin, 1 $\mu \mathrm{M}$ (Sigma); STI571, $3.3 \mu \mathrm{M}$ (gift from Dr. W. Bornmann, MD Anderson Cancer Center, Houston, TX)] were added to media before plating cells. Cells were fixed $24 \mathrm{~h}$ after plating (1 DIV), and coverslips were mounted on slides as described above.

Cultured cortical neurons were immunostained with $\alpha$-Abl (K-12; 4 $\mu \mathrm{g} / \mathrm{ml}$; Santa Cruz Biotechnology), $\alpha$-Arg, or $\alpha$-microtubule-associated protein 2 (MAP2) (1:1000; Chemicon) antibodies as follows. Cells were rinsed in warm PHEM buffer (60 mM PIPES, 25 mM HEPES, $10 \mathrm{~mm}$ EDTA, $2 \mathrm{mM} \mathrm{MgCl}_{2}, \mathrm{pH}$ 6.9), fixed in warm 4\% paraformaldehyde/4\% sucrose in PBS for 10 min at room temperature, rinsed again in PHEM buffer, permeabilized in $0.5 \%$ Triton X-100 in PBS for 10 min at room temperature, and then incubated in primary antibody for $1.5 \mathrm{~h}$ at $37^{\circ} \mathrm{C}$, followed by Alexa- 488 goat- $\alpha$-rabbit or rhodamine-goat- $\alpha$-rabbit secondary antibody ( $1 \mu \mathrm{g} / \mathrm{ml}$; Molecular Probes) for $1.5 \mathrm{~h}$ at $37^{\circ} \mathrm{C}$.

Timelapse analysis. Cortical neurons were prepared as described above and plated on coverslip-bottom dishes (MatTek, Ashland, MA) coated with polyornithine or laminin as described above. Cells were imaged in phase contrast with a $20 \times$ objective at $40 \mathrm{~min}$ intervals on day 1 in vitro or at 7 and $17 \mathrm{~h}$ intervals from 1 to 4 DIV. Cells were returned to the incubator $\left(37^{\circ} \mathrm{C}, 5 \% \mathrm{CO}_{2} / 95 \% \mathrm{O}_{2}\right)$ between imaging times, so that they were never in ambient air for $>15$ min during imaging. Neurons were repeatedly identified based on their unique shapes and the pattern of nearby neurons in the same field of view at $10 \times$ magnification. Neurons were traced using Neurolucida software as described above.

\section{Results}

\section{Generation of brain-specific $\mathrm{abl}^{-/-} \mathrm{arg}^{-/-}$mice}

We used Cre/loxP technology to generate mice with brains that lacked both Abl and Arg to test whether they might have functional overlap in the control of neuronal morphogenesis. Briefly, we engineered into the mouse germline a conditional $a b l$ allele 
$\left(a b f^{l o x}\right)$, crossed it into an $\mathrm{arg}^{-/-}$background, and inactivated $a b l$ using a nestin promoter-Cre recombinase transgene (supplemental Fig. 1, available at www.jneurosci.org as supplemental material). We refer to these $a b f^{\text {flox/flox }} \mathrm{arg}^{-/-}$nestin-Cre $e^{+}$mice as brain specific-double knock-out (bs-dko) mice. The brains of abflox/flox nestin-Cre ${ }^{+}$mice contain no kinase-active Abl protein but yield small amounts of a kinase-inactive Abl mutant protein (supplemental Fig. 2, available at www.jneurosci.org as supplemental material).

\section{Neuronal packing density is increased in}

\section{brain-specific-double knock-out mouse cortex}

Our initial visual analysis suggested that cerebral cortices from bs-dko mice have increased neuronal density relative to gendermatched littermate control mice. We used quantitative stereological sampling techniques to estimate the cortical volume and total number of cortical neurons in 6- to 8-week-old control and bs-dko brain sections stained for the neuron-specific antigen NeuN (Fig. $1 A-D$ ). We found that total neuron density in the cortex is increased by $23 \%$ in bs-dko brains relative to control mice ( $p=0.03$; Student's $t$ test; $n=5$ control and 5 bs-dko mice). This increased cortical neuron density results from nearly identical numbers of neurons occupying decreased cortical volumes in the bs-dko mice (Fig. 1E) (data not shown). To determine whether the increased neuron density was diffuse or layer specific, we also examined cell density by layer in control and bs-dko brains. Neurons in all layers of bs-dko cortex were more densely packed than in controls, with layers 4 and 5 exhibiting significant increases in neuron density (Fig. $1 F$ ).

Increased neuronal density could result from a decrease in glial cell size or number. To test this possibility, we stained control and bs-dko cortices with anti-S-100 $\beta$ antibodies to label astrocytes. We observed no gross morphological alterations in glial cells in bs-dko cortices (Fig. 1G,H) and no difference in glial cell density between control and bs-dko cortices (control, $3.93 \pm$ $0.3 \times 10^{4} \mathrm{glia} / \mathrm{mm}^{3}$; bs-dko, $4.13 \pm 0.16 \times 10^{4} \mathrm{glia} / \mathrm{mm}^{3} ; n=3$ mice; nine sections total for each genotype; $p=0.56$, Student's $t$ test). In addition, $\mathrm{Abl}$ and $\mathrm{Arg}$ are expressed in neurons but not in glia (Moresco et al., 2003), further supporting the hypothesis that decreased neuronal size leads to increased neuronal packing density. These data suggest that neurons in the bs-dko cortex are smaller on average than those in control brains.

\section{Cortical lamination is normal in bs-dko mice}

The failure of neurons to migrate to their proper positions in the cortex could lead to increased cell density in specific layers. To determine whether defects in cortical lamination contribute to increased cell density in bs-dko mice, we labeled a cohort of neurons in bs-dko cortices on E12.5 or E15.5 by BrdU incorporation and examined the distribution of these neurons in the cortex at P21 (supplemental Fig. 3, available at www.jneurosci.org as supplemental material). Neurons labeled on E12.5 migrate to similar positions in the deep layers of the cortex in both bs-dko and littermate control mice (supplemental Fig. $3 A, B, E$, available at www.jneurosci.org as supplemental material). Neurons labeled on E15.5 migrate similarly to the superficial layers of the cortex in both bs-dko and littermate control mice (supplemental Fig. $3 C, D, E$, available at www.jneurosci.org as supplemental material). These data indicate that increased cell density in bs-dko cortices is not a result of defects in cortical lamination.
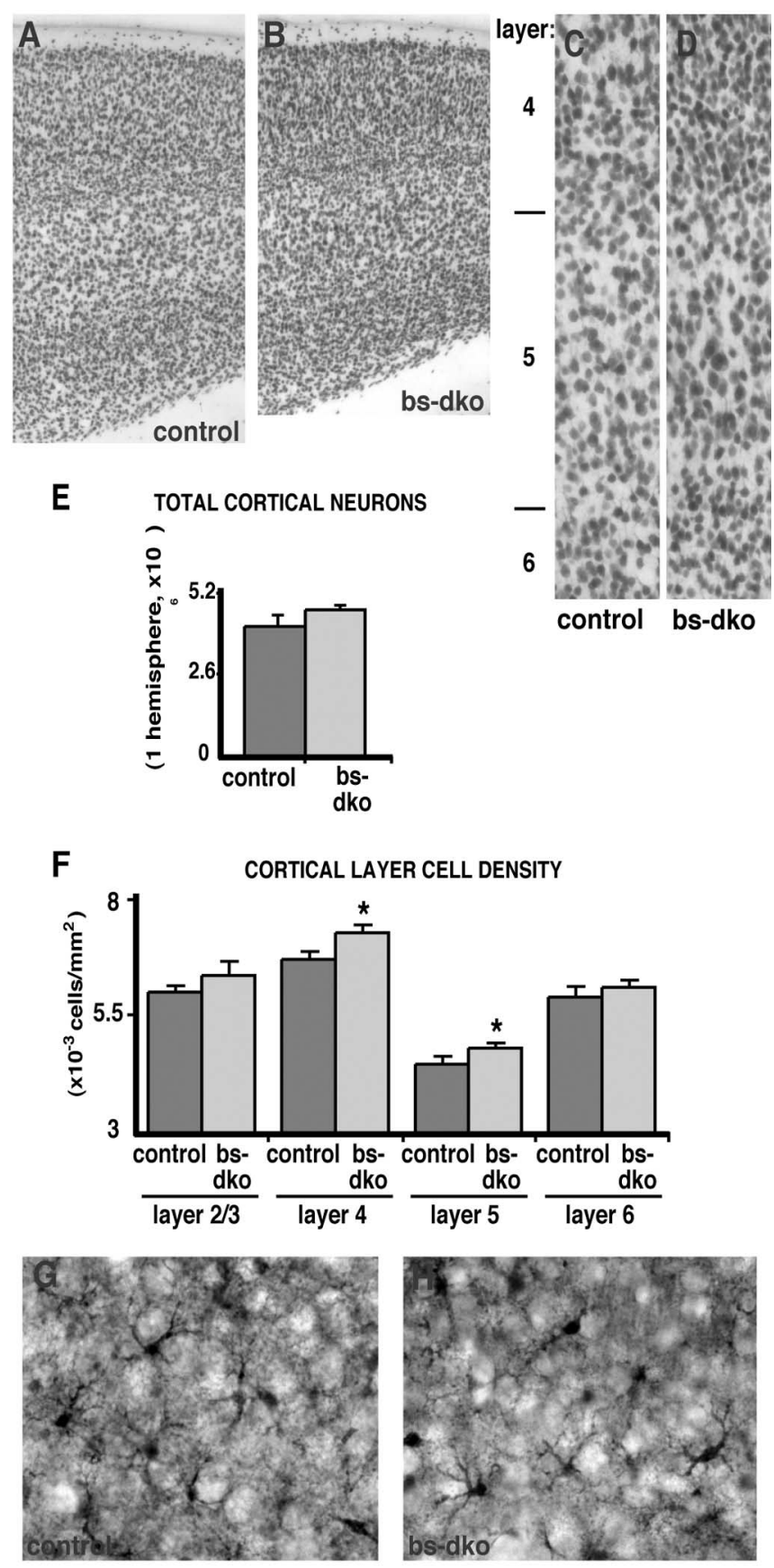

Figure 1. Neuronal density is increased in bs-dko cortices. $\boldsymbol{A}, \boldsymbol{B}$, Sagittal sections (50 $\mu \mathrm{m})$ from 6-week-old $a b l^{+/+} \mathrm{arg}^{+/-}$(control) $(\boldsymbol{A})$ and bs-dko $(\boldsymbol{B})$ littermate mice are stained with antibodies to the neuronal marker NeuN. Sections show a portion of the cortex and are oriented with pial surface at the top. $\boldsymbol{C}, \boldsymbol{D}$, Magnified view of control (C) and bs-dko (D) sections. Cortical layer divisions are indicated on the left. $\boldsymbol{E}$, Quantitation of the number of cortical neurons in control or bs-dko mice. Mean $\pm \mathrm{SE} ; n=5$ mice; $9-12$ sections each per genotype. $\boldsymbol{F}$, Quantitation of cortical neuron density by cortical layer in control or bs-dko mice. Mean $\pm S E ; n=5$ mice per genotype. ${ }^{*} p \leq 0.05$, Student's $t$ test of bs-dko relative to control. $\boldsymbol{G}, \boldsymbol{H}$, Coronal sections $(50 \mu \mathrm{m})$ from 6-week-old $a b l^{+/+} \arg ^{+/-}$(control) $(\boldsymbol{G})$ and bs-dko $(\boldsymbol{H})$ littermate mice are stained with antibodies to the glial marker $\$ 100-\beta$. Sections show a portion of cortical layer 5 .

Adult cortical pyramidal neurons lacking Arg or both Abl and Arg have smaller dendrite arbors

Neurons in bs-dko cortex might have smaller dendrite arbors, allowing them to pack more densely together. Our studies indicated that the increased neuronal density in bs-dko mice is great- 
A

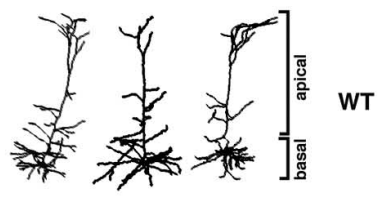

B

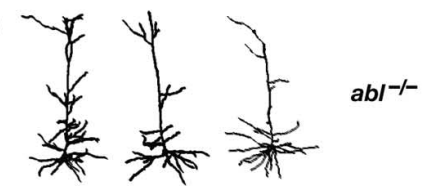

C
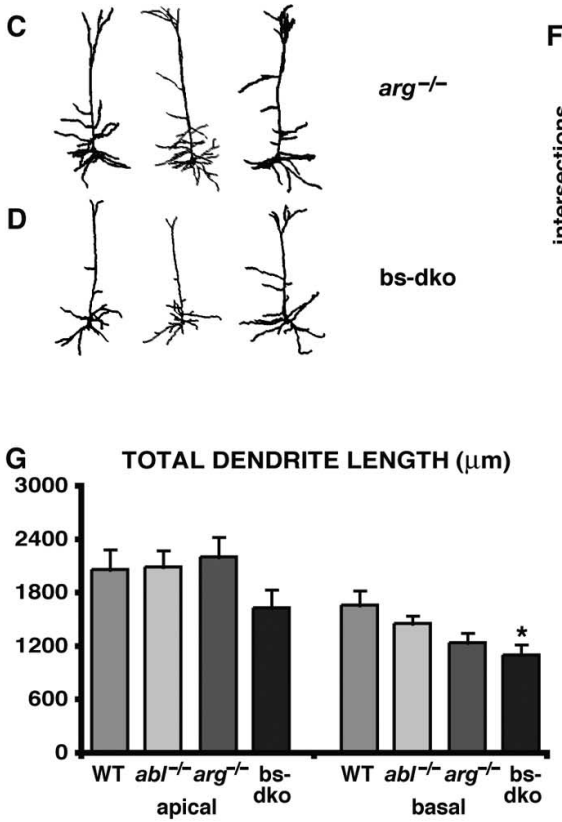
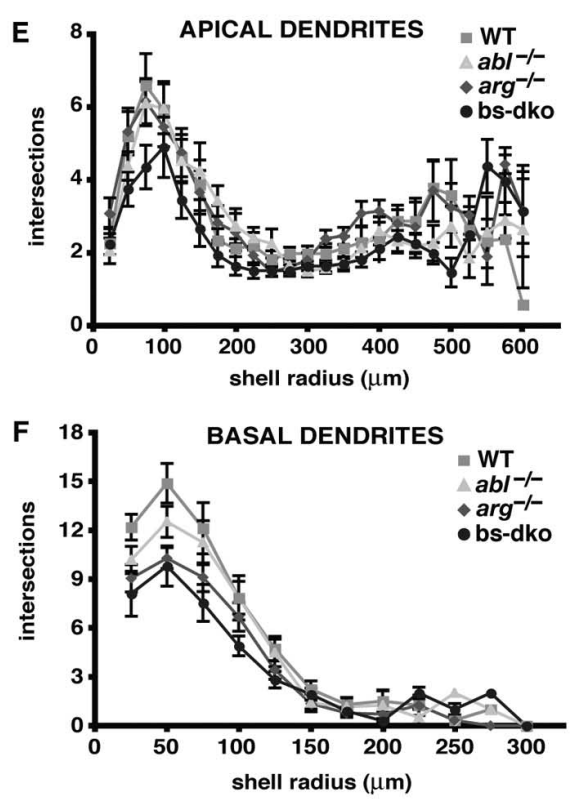

Figure 2. Dendrite arbors are reduced in adult $a b I^{-1-}, a r g^{-1-}$, and bs-dko mice. $A-D$, Camera lucida drawings of representative wild-type $(\boldsymbol{A}), a b l^{-/-}(\boldsymbol{B}), \arg ^{-/-}(\boldsymbol{C})$, and bs-dko $(\boldsymbol{D})$ layer 5 pyramidal neurons from 6- to 8-week-old mice. Apical and basal dendrite arbors are indicated for a wild-type neuron in $\boldsymbol{A}$. $\boldsymbol{E}, \boldsymbol{F}$, Sholl analysis of apical $(\boldsymbol{E})$ and basal $(\boldsymbol{F})$ dendrites from wild-type, $\left.a b\right|^{-1-}, a r g^{-1-}$, and bs-dko layer 5 pyramidal neurons. Sholl analysis measures dendrite complexity: concentric three-dimensional shells of increasing radius are centered on the cell body of the neuron; the number of intersections of the dendrite arbor with a given shell is plotted versus the shell radius. Each point represents mean $\pm \mathrm{SE}$. For all data presented in this figure, analysis was performed on the following: apical dendrites, wild type, $n=6$ mice, 16 neurons; $a b l^{-1-}, n=4$ mice, 15 neurons; $\mathrm{arg}^{-1-}, n=4$ mice, 16 neurons; bs-dko, $n=6$ mice, 17 neurons; basal dendrites, wild type, $n=6$ mice, 16 neurons; $a b l^{-/-}, n=4$ mice, 16 neurons; arg $^{-/-}, n=4$ mice, 17 neurons; bs-dko, $n=6$ mice, 16 neurons. $\boldsymbol{G}, \boldsymbol{H}$, Mean total length $(\boldsymbol{G})$ and branchpoint number $(\boldsymbol{H})$ of apical (left) and basal (right) dendrite arbors from wild-type, $a b l^{-1-}, a^{-1-}{ }^{-1}$, and bs-dko layer 5 pyramidal neurons. Mean \pm SE. ANOVA between all genotypes: apical length, $p=0.233$; basal length, $p=0.014$; apical branchpoints, $p=0.092$; basal branchpoints, $p<0.0001$; post hoc Student-Newman-Keuls test for each mutant versus wild type, ${ }^{*} p<0.05$.

est in cortical layers 4 and 5. We used Golgi-Cox staining followed by camera lucida reconstruction to investigate the structures of layer 5 pyramidal neurons in the somatosensory and visual cortices of adult mice lacking $\mathrm{Abl}$ and/or $\operatorname{Arg}$ (Fig. $2 A-D$ ).

Both Sholl and morphometric analyses revealed that layer 5 pyramidal neurons in 6- to 8-week-old $\mathrm{arg}^{-/-}$mice have smaller basal dendrite arbors compared with wild-type controls (Fig. $2 C, F-H)$. Quantitation revealed that the total length of basal dendrites is reduced by $26 \%$ in $\mathrm{arg}^{-/}$neurons compared with wild-type neurons (Fig. 2G). These smaller basal dendrite arbors have $28 \%$ fewer dendrite branchpoints (Fig. $2 H$ ) and a commensurate decrease in the number of basal dendrite segments compared with wild-type arbors (data not shown). Interestingly, the apical dendrites of $\mathrm{arg}^{-/-}$cortical neurons were similar to wildtype apical dendrites in length and branchpoint number (Fig. $2 G, H)$. The total length and branchpoint number of basal dendrites from $a b l^{-1-}$ layer 5 pyramidal neurons were reduced by 13 and $15 \%$, respectively, relative to wildtype neurons, although this reduction was not statistically significant (Fig. $2 B, G, H$ ).

We also examined the bs-dko mice to determine whether Abl and Arg have overlapping functions in the control of dendrite morphogenesis. The bs-dko cortical layer 5 neurons have more severe reductions in their basal dendrite arbors than either $a b l^{-1-}$ or $\mathrm{arg}^{-/-}$neurons (Fig. $2 D, F)$. The total basal dendrite length is reduced $34 \%$ in bs-dko neurons relative to wild-type neurons (Fig. 2G). Dendrite branchpoint number is also decreased by $45 \%$ in bs-dko neurons relative to wild type (Fig. $2 H$ ). The finding that basal dendrite arbors are further reduced in bs-dko neurons compared with $\mathrm{abl}^{-1-}$ or $\mathrm{arg}^{-1-}$ neurons suggests that $\mathrm{Abl}$ and Arg have overlapping roles in the regulation of dendrite arbor formation. Both Sholl and morphometric analyses indicate that apical dendrite arbors are smaller in bs-dko neurons relative to wild-type neurons (Fig. $2 E, G)$. Apical dendrite arbors are $21 \%$ shorter in bs-dko neurons than in wildtype neurons and have a $32 \%$ decrease in dendrite branchpoints (Fig. 2G,H), suggesting an additive or interactive effect for $\mathrm{Abl}$ and Arg specific to apical dendrites.

Previous studies have shown that $\mathrm{Abl}$ and Arg are expressed abundantly in neurons of the developing and mature brain (Koleske et al., 1998; Moresco et al., 2003). We examined whether differences in $\mathrm{Abl}$ or Arg expression levels might explain the differential requirements for the kinases in dendrite development. We used semiquantitative immunoblot analysis with purified recombinant $\mathrm{Abl}$ and Arg as standards to determine the relative amount of $\mathrm{Abl}$ and Arg in the mouse brain at several developmental time points. This analysis revealed that $\mathrm{Abl}$ is fivefold more abundant than Arg in brain extracts made at E13, but that Arg is eightfold more abundant than Abl in the brain at P21 and fivefold more abundant than Abl in the 6-week-old brain (Fig. 3). Because most dendrite growth occurs postnatally, the finding that Arg is more abundant in postnatal brain may explain why the loss of Arg function has greater effects on dendrite arbors than the loss of Abl function.

In summary, basal dendrites are more severely affected by the loss of Abl and/or Arg than apical dendrites. The loss of Arg function leads to more severe defects than the loss of Abl function, and mice lacking both kinases are affected even more severely. These data indicate that Abl and Arg have overlapping functions in the control of both apical and basal dendrite length and branching.

Cortical pyramidal neurons have normal dendrite arbors in $\mathrm{arg}^{-/-}$and bs-dko mice at P21

To better understand which periods of dendrite development require $\mathrm{Abl}$ and $\mathrm{Arg}$ function, we also measured dendrite arbors 
in wild-type, $\mathrm{arg}^{-1-}$, and bs-dko mouse brains at P21, just after the period of the most extensive dendrite growth in mouse cortex (Miller, 1988). Both Sholl and morphometric analyses indicate that P21 wildtype neurons develop elaborate apical and dendrite arbors that are greater in total length and have more branchpoints than adult neurons. For example, apical dendrite arbors have $45 \%$ increased total length and 35\% increased branchpoint number in $\mathrm{P} 21$ wild-type neurons relative to adult wild-type neurons. Basal dendrite arbors are also slightly increased in P21 wild-type neurons relative to adult wildtype neurons (compare Fig. $2 G, H$ with Fig. $4 F, G$ ).

Interestingly, the apical and basal dendrite arbors of P21 $\mathrm{arg}^{-1-}$ and bs-dko neurons are similar in size and complexity to those of P21 wild-type mice (Fig. $4 A-G$ ). For example, the total apical and basal dendrite length and the number of apical and basal branchpoints do not differ significantly between P21 wildtype, $\arg ^{-1-}$, and bs-dko cortical pyramidal neurons. Not surprisingly, cortical neuron density is similar between control and bs-dko cortex in P21 mice (data not shown). Together with results presented in Figure 2, our findings suggest that $\mathrm{arg}^{-/-}$and bs-dko pyramidal neurons initially form normal dendrite arbors, but that dendrite arbors are maintained with reduced efficiency in the $\mathrm{arg}^{-1-}$ and bs-dko mice.

\section{Axon afferents to the cortex are normal in $\mathrm{arg}^{-/-}$and bs-dko brains}

Previous studies have shown that Abl family kinases can regulate axon guidance and growth (Gertler et al., 1989; Elkins et al., 1990; Giniger, 1998; Wills et al., 1999a,b; Bashaw et al., 2000). Because synaptic activity from afferent axons can promote dendrite maintenance (McAllister, 2000; Lohmann et al., 2002; Redmond et al., 2002; Vaillant et al., 2002; Whitford et al., 2002), we examined whether $\mathrm{arg}^{-/-}$and bs-dko brains have defects in afferent axons innervating cortical layer 4 and 5 neurons that might lead to secondary defects in dendrite branch maintenance.

Thalamic axons reaching the cortex via the internal capsule are the main afferent inputs to layer 4 neurons, whereas layer 5 neurons receive their principal afferent inputs from homotypic contralateral neurons via the corpus callosum (Innocenti, 1986; Naegele et al., 1988; Miller et al., 1993). We immunostained coronal sections from 6- to 8-week-old littermate control and bs-dko mice with anti-Ig superfamily adhesion receptor L1 (anti-L1) antibodies to reveal the size and morphology of the corpus callosum and internal capsule. Both the corpus callosum and the internal capsule appear similar in matched sections from 6- to 8 -week-old control and bs-dko mice (Fig. 5A-F). The thickness of the corpus callosum reflects the number of axons crossing to contralateral cortical hemispheres. We measured corpus callosum thickness in control and bs-dko mice to determine whether bs-dko mice have significantly reduced numbers of corticocortical axons that could lead to dendrite arbor deterioration. Mean corpus callosum thickness in matched coronal sections was similar in 6- to 8-week-old control and bs-dko mice (Fig. $5 H$ ). These data suggest that axon numbers and morphology are normal in the absence of Abl and Arg.

We reasoned that failures in axon growth or guidance might precede the deterioration of dendrites observed in $\mathrm{arg}^{-/-}$and bs-dko cortices. To address this possibility, we performed anti-L1

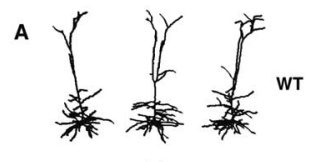

B

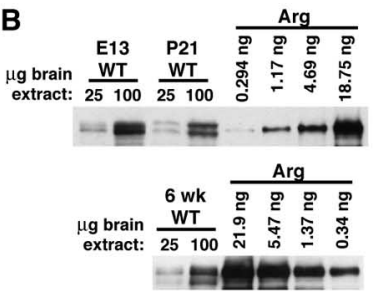

\begin{tabular}{l|cc} 
C & Abl (ng) & Arg (ng) \\
\hline E13 & 20 & 3.6 \\
P21 & 1.2 & 9 \\
6 wk & 0.3 & 1.4
\end{tabular}
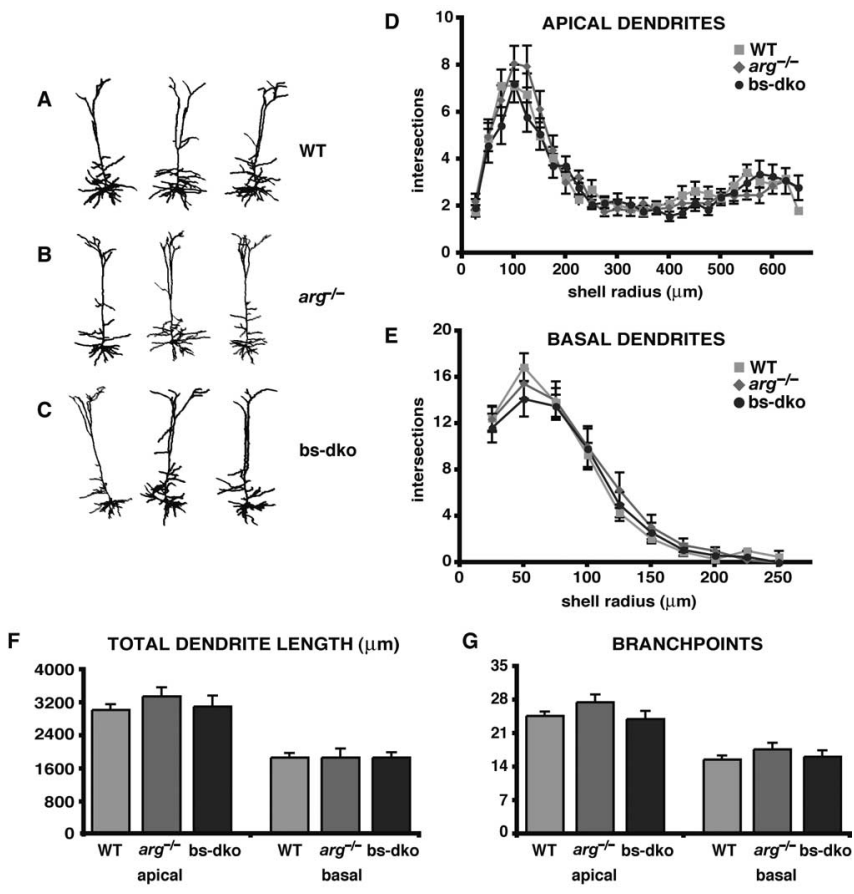

Figure 4. Dendrite arbors are normal in $\mathrm{arg}^{-/-}$and bs-dko mice at P21. A-C, Camera lucida drawings of representative wild-type $(\boldsymbol{A}), \arg ^{-/-}(\boldsymbol{B})$, and bs-dko $(\boldsymbol{C})$ layer 5 pyramidal neurons from P21 mice. Neurons are oriented as in Figure 3. D, E, Sholl analysis of apical $(\boldsymbol{D})$ and basal $(\boldsymbol{E})$ dendrites from wild-type, $\mathrm{arg}^{-/-}$, and bs-dko layer 5 pyramidal neurons. Each point represents mean $\pm S E$. For all experiments in this figure, analysis was performed on the following: apical dendrites, wild type, $n=6$ mice, 17 neurons; arg $^{-/-}, n=5$ mice, 16 neurons; bs-dko, $n=5$ mice, 15 neurons; basal dendrites, wild type, $n=6$ mice, 17 neurons; arg $^{-1-}$, $n=6$ mice, 17 neurons; bs-dko, $n=6$ mice, 16 neurons. $\boldsymbol{F}, \mathbf{G}$, Mean total length $(\boldsymbol{F})$ and branchpoint number $(\boldsymbol{G})$ of apical (left) and basal (right) dendrite arbors from wild-type, $\arg ^{-/-}$, and bs-dko layer 5 pyramidal neurons. Mean \pm SE. ANOVA between all genotypes: apical length, $p=0.568$; basal length, $p>0.999$; apical branchpoints, $p=0.202$; basal branchpoints, $p=0.436$.

immunostaining of matched coronal sections from control, $\mathrm{arg}^{-1-}$, and bs-dko mice at P18-P22, when dendrites have elaborated but are not fully mature (data not shown). No morphological differences were observed between wild-type, $\mathrm{arg}^{-/-}$, and bs-dko corpus callosa or internal capsules. Quantitation of these sections revealed similar mean corpus callosum thickness in wild-type, $\mathrm{arg}^{-/-}$, and bs-dko brains (Fig. 5G).

Finally, to examine axon trajectories as they defasciculate from the corpus callosum, we anterogradely labeled callosal axons in P18-P22 wild-type, arg $^{-1-}$, and bs-dko brains using the axon tracer DiI. We observed no gross abnormalities in callosal axons as they crossed the midline, entered the contralateral cor- 

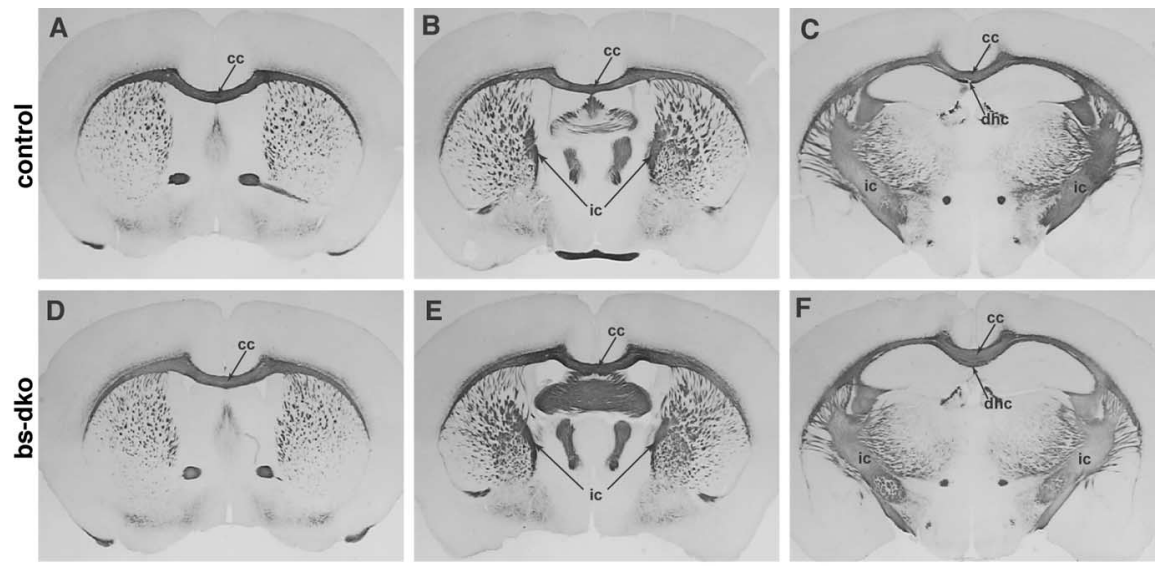

\section{G P18-22 CORPUS CALLOSUM MEAN THICKNESS $(\mu \mathrm{m})$}
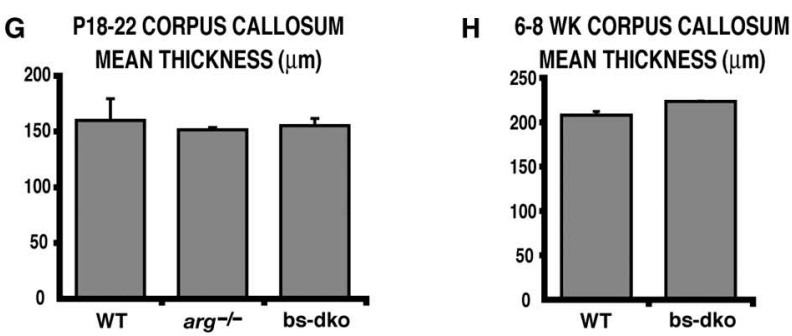

I
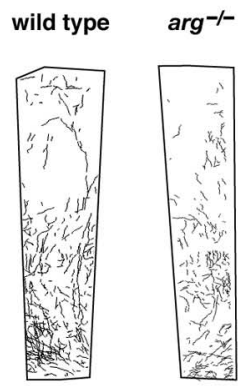

bs-dko

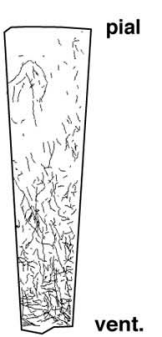

$\mathbf{J}$

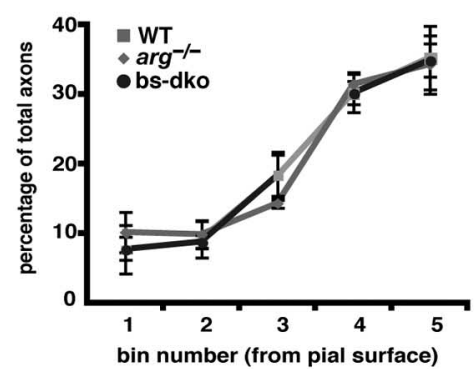

Figure 5. Cortical afferents appear normal in $\arg ^{-/-}$and bs-dko mice. $\boldsymbol{A}-\boldsymbol{F}$, The major cortical afferent tracts were stained with anti-L1 antibodies in matched coronal sections from adult control $\left(a b^{+/+} \arg ^{+/-}\right)(\boldsymbol{A}-\boldsymbol{C})$ and bs-dko $(\boldsymbol{D}-\boldsymbol{F})$ mice. The corpus callosum (cc), internal capsule (ic), and dorsal hippocampal commissure (dhc) are indicated. $\mathbf{G}, \boldsymbol{H}$, Mean corpus callosum thickness from four to six matched coronal sections each from P18 -P22 (G) and adult $(\boldsymbol{H})$ control $\left(\mathrm{abl}^{+/+} \mathrm{arg}^{+/-}\right)$, $\mathrm{arg}^{-/-}$, or bs-dko mice. Mean thickness is similar for all genotypes. P18-P22, $n=4$ mice; adult, $n=4$ mice. ANOVA between all genotypes in $\mathbf{G}, p=0.88$; Student's test for bs-dko versus control in $\boldsymbol{H}, p=0.16 . \boldsymbol{I}, \mathbf{J}$, Cortical axons were labeled by placement of a Dil crystal into the contralateral visual cortex. Representative tracings of axons in wild-type, $\mathrm{arg}^{-1-}$, and bs-dko cortex are shown in $I$. Each cortical section was overlaid with five equally sized bins that spanned area from the pial surface to the corpus callosum. The percentage of total axons in each bin is presented in $J$. Mean $\pm \mathrm{SE}, n=2$ mice, four sections each per genotype. ANOVA between all genotypes for percentage axons in each bin: $\operatorname{bin} 1, p=0.788$; bin $2, p=0.932$; bin $3, p=0.503$; bin $4, p=0.892$; bin $5, p=$ 0.984 .

tex, and targeted similar cortical areas in wild-type, $\mathrm{arg}^{-/-}$, and bs-dko brains (data not shown). Tracing of individual DiIlabeled callosal axons revealed that corticocortical axons project similarly in wild-type, $\mathrm{arg}^{-1-}$, and bs-dko brains with the majority of callosal axons terminating similarly in the deeper cortical layers (Fig. 5I,J). These data suggest that corticocortical axon projection patterns are essentially unaffected by the loss of Abl/ Arg function. It is possible that subtle defects in intracortical axon connectivity exist but are below the resolution of this analysis.

\section{Arg promotes axon and dendrite branching in cultured cortical neurons}

To better understand how Abl and Arg regulate dendrite maintenance, we examined whether expression of Arg or Arg mutants could affect neuronal morphogenesis in primary cultured cortical neurons. We focused on Arg because of its more significant role than $\mathrm{Abl}$ in regulating dendrite structure. Neurons were cotransfected with expression vectors for Arg and YFP to allow for imaging, tracing, and reconstruction of neurons using camera lucida software.

Neurons overexpressing Arg have more complex neurite structures than control neurons expressing only YFP (Fig. 6B). Quantitation revealed that Arg promotes a $26 \%$ increase in the number of neurite branchpoints (Fig. 6C). The neurites of Arg-overexpressing neurons are similar in length to control neurons (Fig. $6 C$ ). This leads to an overall $25 \%$ increase in branchpoint density (branchpoints per unit length of neurite) compared with control YFP-expressing neurons (Fig. 6E). Control and Arg-overexpressing neurons contain similar numbers of primary neurites (neurites extending directly from the cell body) per neuron (YFP control, $5.55 \pm 0.17$; YFP plus Arg, $6.13 \pm 0.18$ ). These results demonstrate that Arg can act within neurons to increase neurite branching.

\section{Arg requires its kinase activity to promote neurite branching}

A kinase-inactive Arg point mutant (ArgKI) (Hernandez et al., 2004a) did not increase neurite branchpoint number or length over that observed in control neurons (Fig. 6C). Conversely, overexpression of an Arg mutant with elevated kinase activity [Arg $\Delta \mathrm{Src}$ homology 3 (SH3)] increased neurite branchpoints by $26 \%$ and decreased total neurite length by $15 \%$ (Fig. $6 C)$. Together, these factors contribute to a $37 \%$ increase in branchpoint density in Arg $\Delta \mathrm{SH} 3$-expressing neurons compared with control neurons (Fig. 6E). These data indicate that Arg requires its kinase activity to promote neurite branching in vitro. Interestingly, an Arg C-terminal truncation mutant lacking the two F-actinbinding domains and the microtubule-binding domain $(\operatorname{Arg} \Delta \mathrm{C})$ (Miller et al., 2004) increases branchpoint density by 30\% (Fig. $6 A, C-E)$. These data indicate that the cytoskeletal-binding domains are not required for Arg to promote neurite branching, at least when overexpressed.

\section{Arg promotes branching of both axons and dendrites}

We investigated whether Arg affects axon or dendrite branching in vitro. Previous work by Szebenyi et al. (1998) and Dent et al. (1999) demonstrated that at $3 \mathrm{~d}$ in culture, the longest neurite on cortical neurons is the axon. In agreement with these previous reports, we found that at $4 \mathrm{~d}$ in vitro, cortical neurons have a single long axon with an average length of 400-500 $\mu \mathrm{m}$ (Fig. $6 \mathrm{E}$ ) and several shorter dendrites with average lengths of 50-60 $\mu \mathrm{m}$ 
A

\begin{tabular}{|c|c|c|c|c|c|}
\hline Arg & \begin{tabular}{l|l}
3 & 2 \\
\end{tabular} & Kinase & $F$ & MT & $\mathbf{F}$ \\
\hline \multicolumn{6}{|c|}{ K317R } \\
\hline ArgKI & \begin{tabular}{l|l|l|}
3 & 2
\end{tabular} & Kinase & $\mathbf{F}$ & MT & $\mathbf{F}$ \\
\hline
\end{tabular}

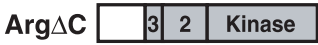

$\operatorname{Arg} \Delta \mathrm{SH} 3 \quad \square \quad$\begin{tabular}{|l|l|l|l|l|l|}
\hline 2 & Kinase & & F & MT & F \\
\hline
\end{tabular}

B

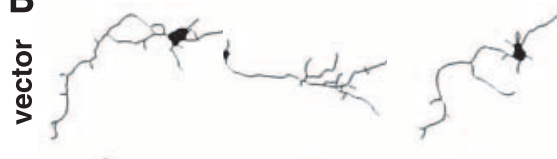<smiles>CC(C)CC1CC1CC(C)C</smiles><smiles>CCC(C(C)C)C(CC(C)C)C(C)C</smiles>

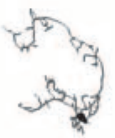

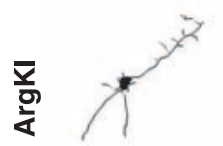<smiles>CC[Te]C</smiles>

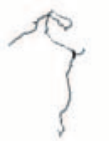
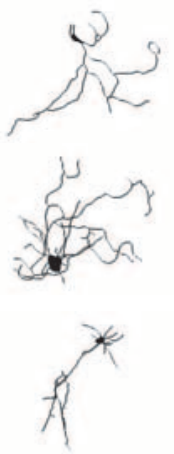

C
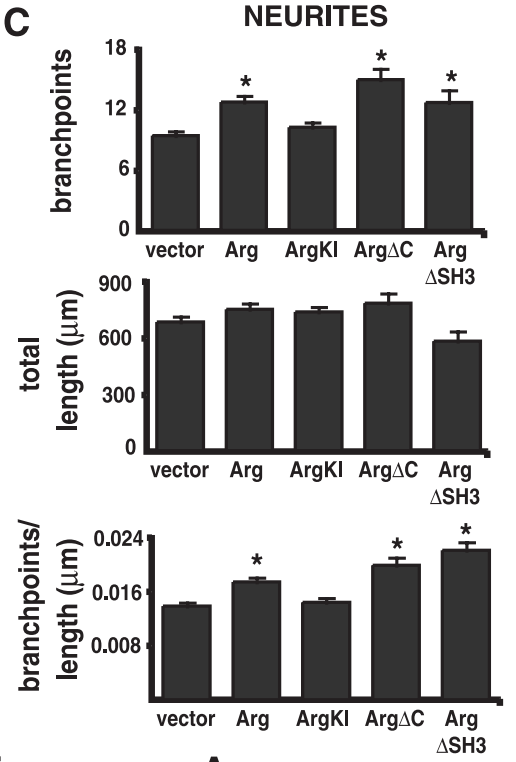

$\mathbf{F}$
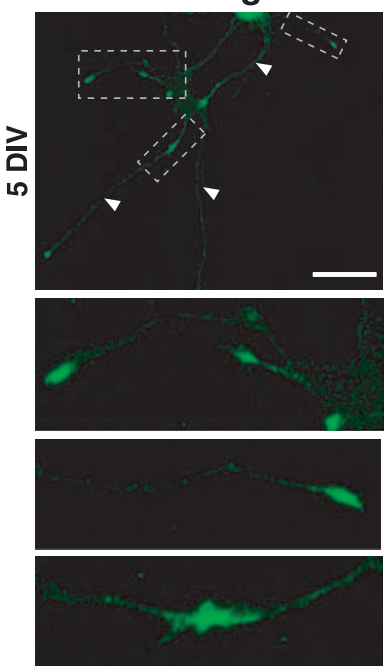

D
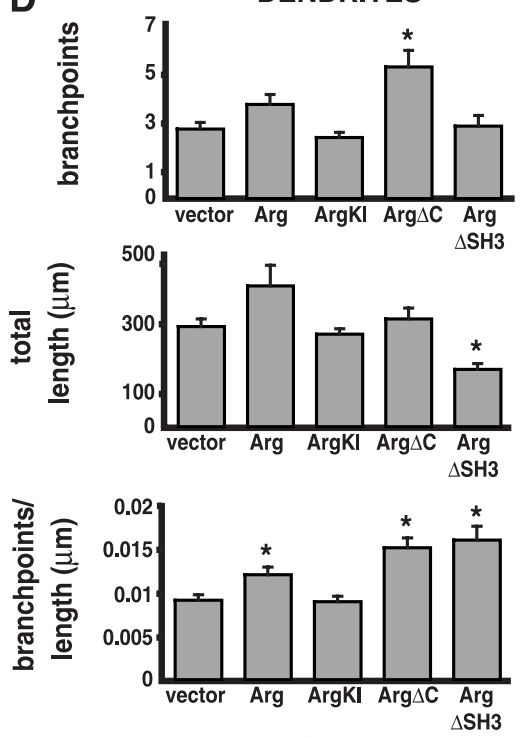

G
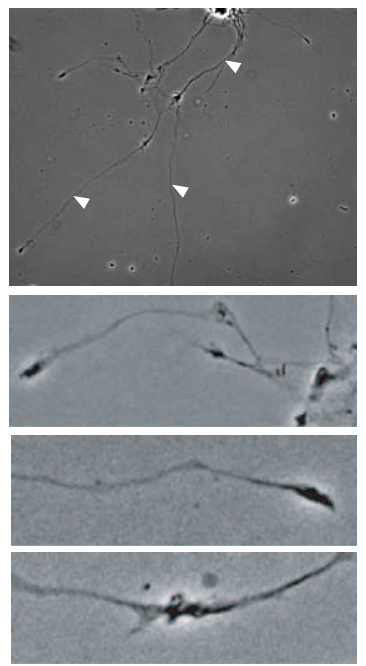

E
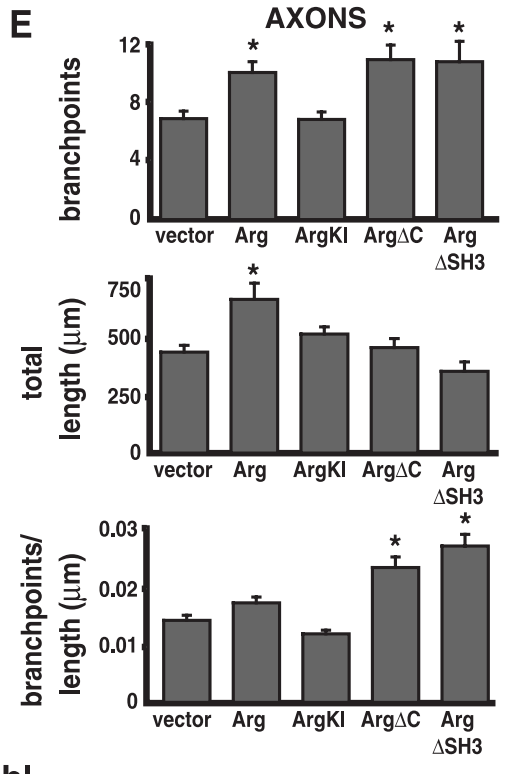

$\alpha-A b \mid$

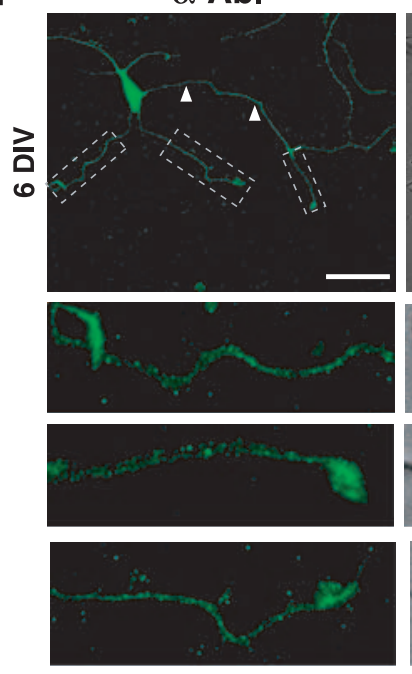

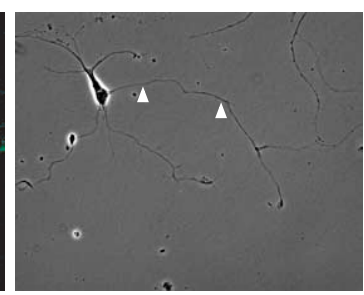
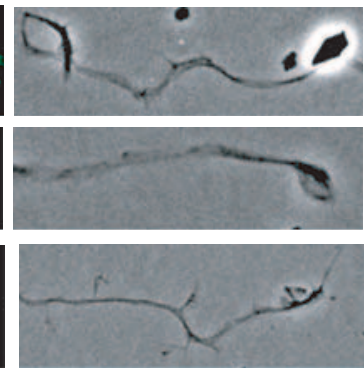

Figure 6. Arg promotes axon and dendrite branching in cultured cortical neurons. A, Diagram of Arg and Arg mutants used in these assays. The Arg N-terminal half contains SH3 (3), $\mathrm{SH} 2$ (2), and kinase domains. The Arg C-terminal half contains two F-actin-binding domains $(\boldsymbol{F})$ and a microtubule-binding domain (MT). ArgKI has a point mutation rendering it kinase inactive. Arg $\Delta C$ lacks the cytoskeleton-binding domains. Arg $\Delta$ SH3 has a deletion of the SH3 domain, rendering it hyperactive for kinase activity. $B$, Camera lucida drawings of cortical neurons transfected with vector alone or with expression vectors for Arg and ArgKI made at 4 DIV. $(-E$, Quantitation of branchpoint number, total length, and branchpoints/length for neurites $(\boldsymbol{C})$, dendrites $(\boldsymbol{D})$, and axons $(\boldsymbol{E})$ in neurons expressing vector alone or expression vectors for Arg, $\operatorname{ArgKl}, \operatorname{Arg} \Delta C$, and $\operatorname{Arg} \Delta S H 3$. All values represent mean \pm SE. C, Vector, $n=202$ neurons, eight transfections; Arg, $n=197$ neurons, eight transfections; ArgKl, $n=187$ neurons, six transfections; $\operatorname{Arg} \Delta C, n=93$ neurons, six transfections; Arg $\Delta S H 3, n=53$ neurons, four transfections. D, E, Vector, $n=126$ neurons, five transfections; $\operatorname{Arg}, n=123$ neurons, five transfections; ArgKI, $n=123$ neurons, four transfections; $\operatorname{Arg} \Delta C, n=81$ neurons, four transfections; $\operatorname{Arg} \Delta \mathrm{SH} 3, n=45$ neurons, three transfections. For neurites, ANOVA between all transfection conditions is as follows: branchpoints, $p<0.0001$; length, $p=0.035$; branchpoints/length, $p<0.0001$. For dendrites, ANOVA between all transfection conditions: branchpoints, $p<0.0001$; dendrite length, $p=0.0023$; branchpoints/length, $p<0.0001$. For axons, ANOVA between all transfection conditions is as follows: branchpoints, $p<0.0001 ;$ axon length, $p=$ 0.0002; branchpoints/length, $p<0.0001$. Posthoc Student-Newman-Keuls test for each Arg construct versus vector alone: ${ }^{*} p<0.05$. E, $\boldsymbol{F}$, Cultured cortical neurons immunostained with $\alpha$-Arg $(\boldsymbol{E})$ or $\alpha$-Abl $(\boldsymbol{F})$ antibodies at 5 or 6 DIV. Phase-contrast images are shown in the right panels. Axons are indicated by white arrowheads. Boxed regions are enlarged below each image. Endogenous Arg is concentrated in growth cones and at phase-dense spots along neurites. Endogenous Abl is present more homogeneously throughout neurites, with a slight concentration in the growth cone. Scale bars, $40 \mu \mathrm{m}$. 

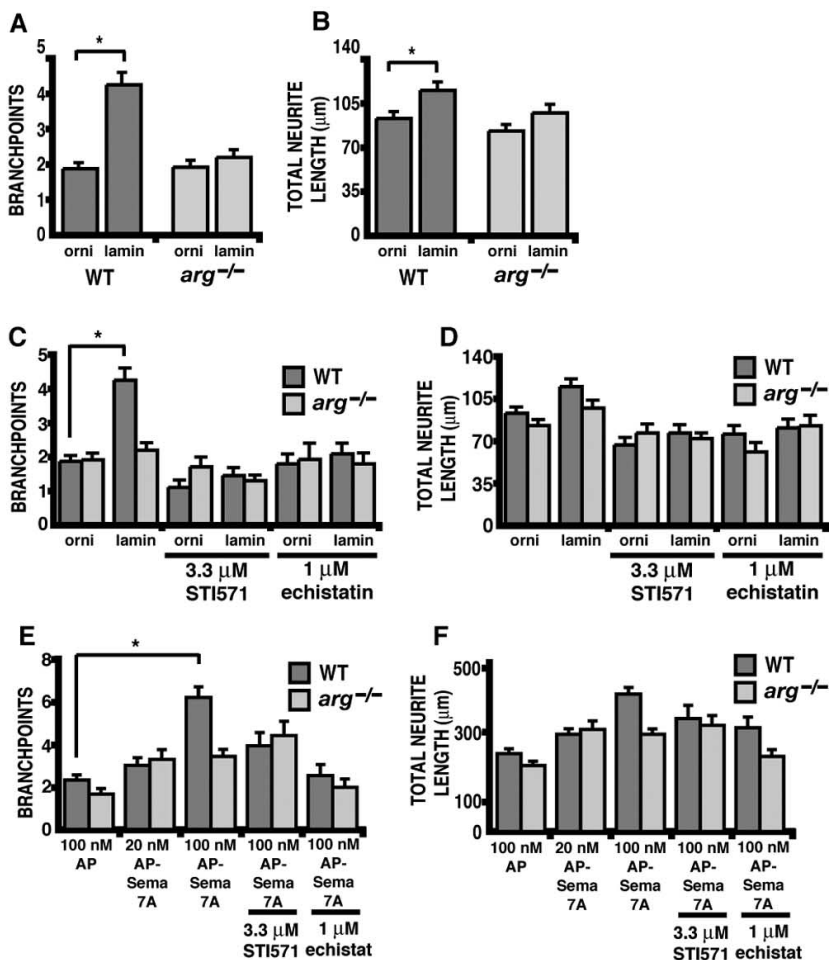

$\mathbf{F}$
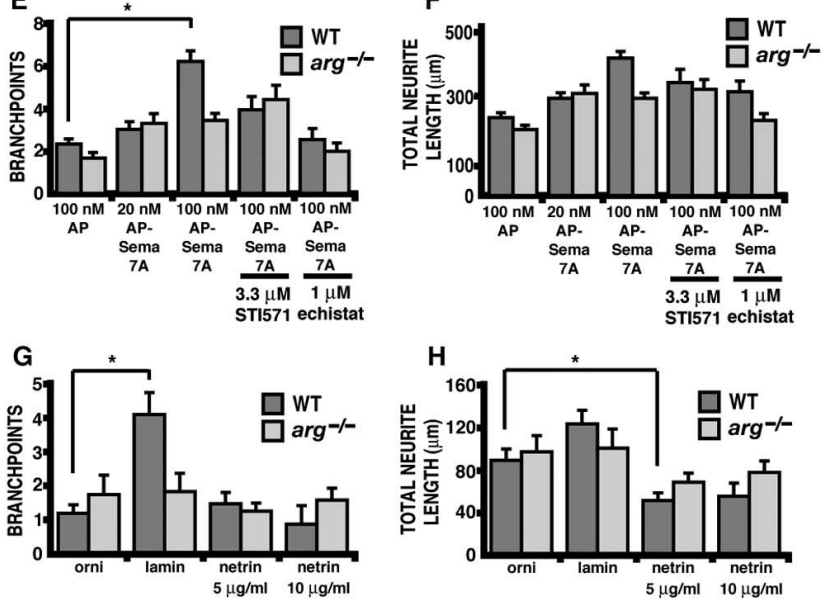

Figure 7. Arg is required for integrin-mediated neurite branching. Bar diagrams indicate mean branchpoint number $(\boldsymbol{A}, \boldsymbol{C}, \boldsymbol{E})$ and total neurite arbor length $(\boldsymbol{B}, \boldsymbol{D}, \boldsymbol{F})$. All values represent mean \pm SE. $\boldsymbol{A}, \boldsymbol{B}$, Wild-type or $\mathrm{arg}^{-1-}$ cortical neurons were plated on glass coverslips coated with polyornithine (ornithine) or polyornithine plus laminin-1 (laminin). Neurons were fixed at $24 \mathrm{~h}$ and traced with camera lucida software. Wild type on ornithine, $n=150$ total neurons, five independent experiments; wild type on laminin, $n=136$ neurons, five experiments; arg $^{-/-}$ on ornithine, $n=137$ neurons, five experiments; arg $^{-/-}$on laminin, $n=128$ neurons, five experiments. $\boldsymbol{C}, \boldsymbol{D}$, Wild-type or $\mathrm{arg}^{-/-}$cortical neurons plated on ornithine or laminin in the presence of the Abl/Arg inhibitor STI571 (3.3 $\mu \mathrm{m}$ ) or the $\beta 1 / \beta 3$ integrin inhibitor echistatin (1 $\mu \mathrm{m})$. Wild-type on ornithine plus echistatin, $n=61$ neurons, three experiments; wild type on laminin plus echistatin, $n=59$ neurons, three experiments, wild type on ornithine plus STI571, $n=61$ neurons, three experiments; wild type on laminin plus STI571, $n=93$ neurons, three experiments; $\mathrm{arg}^{-/-}$on ornithine plus echistatin, $n=20$, one experiment; $\mathrm{arg}^{-/-}$on laminin plus echistatin, $n=59$ neurons, three experiments; $\arg ^{-/}$on ornithine plus STI571, $n=$ 57 neurons, three experiments; arg $^{-/}$on laminin plus STI571, $n=89$ neurons, three experiments. For $\boldsymbol{A}-\boldsymbol{D}$, ANOVA between all plating conditions: branchpoints, $p<0.0001$; length, $p<0.0001$; post hoc Student-Newman-Keuls test for each condition versus wild type plated on ornithine, ${ }^{*} p<0.05$. ANOVA between all plating conditions for each genotype: wild-type branchpoints, $p<0.0001$; arg $^{-1-}$ branchpoints, $p=0.119$; wild-type length, $p<0.0001$; $\mathrm{arg}^{-/-}$length, $p=0.022 . E, F$, Wild type or $\arg ^{-/-}$cortical neurons plated on Semaphorin7A (AP-Sema7A) or control protein (AP) substrates in the presence of STI571 (3.3 $\mu \mathrm{M})$ or echistatin $(1 \mu \mathrm{M})$. Wild type on AP, $n=70$ neurons, four experiments; wild type on $20 \mathrm{~nm}$ Sema7A, $n=$ 46 neurons, two experiments; wild type on $100 \mathrm{~nm}$ Sema7A, $n=72$ neurons, three experiments; wild type on $100 \mathrm{~nm}$ Sema7A plus STI571, $n=27$ neurons, one experiment; wild type on $100 \mathrm{~nm}$ Sema7A plus echistatin, $n=25$ neurons, one experiment; $\mathrm{arg}^{-1-}$ on AP, $n=74$ neurons, three experiments; arg $^{-1-}$ on $20 \mathrm{~nm}$ Sema7 $\mathrm{A}, n=47$ neurons, two experiments; $\mathrm{arg}^{-/-}$on $100 \mathrm{~nm} \mathrm{Sema7A}, n=72$ neurons, three experiments; $\mathrm{arg}^{-/-}$on $100 \mathrm{~nm} \mathrm{Sema7A}$

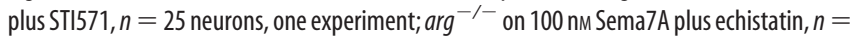
29 neurons, one experiment. For $\boldsymbol{E}$ and $\boldsymbol{F}$, ANOVA between all plating conditions is as follows: branchpoints, $p<0.0001$; length, $p<0.0001$; post hoc Student-Newman-Keuls test for each condition versus wild type plated on $100 \mathrm{~nm} \mathrm{AP,}{ }^{*} p<0.05$. ANOVA between all plating conditions for each genotype: wild-type branchpoints, $p=0.0004 ; \mathrm{arg}^{-/-}$branchpoints, $p=$ 0.015; wild-type length, $p=0.007$; $\mathrm{arg}^{-/-}$length, $p=0.104$. G, $\boldsymbol{H}$, Wild type or $\mathrm{arg}^{-/}$
(Fig. $6 B, D$ ). The short dendritic processes stain positively for the dendrite marker MAP2, whereas the long axonal process is MAP2 negative (supplemental Fig. 4, available at www.jneurosci.org as supplemental material). We cotransfected primary cortical neurons with expression vectors for Arg and YFP at $2 \mathrm{~d}$ in vitro, fixed them at $4 \mathrm{~d}$ in vitro, and then analyzed axon and dendrite morphology. Neurons were cultured at low density to eliminate the contributions of cell-cell contact to neuronal morphogenesis.

Neurons overexpressing Arg have more complex neurite structures than control neurons expressing only the YFP vector (Fig. 6B). Quantitation revealed that control and Argoverexpressing neurons contain similar numbers of primary dendrites per neuron (YFP control, $4.76 \pm 0.22$; YFP plus Arg, $5.29 \pm$ $0.24 ; p=0.11$, Student's $t$ test). Arg-expressing neurons exhibit a $37 \%$ increase in dendrite branchpoints and a 33\% increase in dendrite branchpoint density (branchpoints per micrometer of dendrite) over control YFP-expressing neurons (Fig. 6D). Arg expression also promotes a $46 \%$ increase in axon branchpoints and a 52\% increase in axon length (Fig. $6 E$ ). Together, these data indicate that Arg can promote branching of both axons and dendrites from cortical neurons in vitro.

\section{Arg and Abl localize to axons and dendrites}

Immunofluorescence localization in cultured cortical neurons revealed that increased staining for endogenous Arg is observed in growth cones and in phase-dense thickenings of the dendrite and axon shafts (Fig. 6F). Abl localized along axons and dendrites with slightly elevated staining in the growth cone, as reported previously (Fig. 6G) (Zukerberg et al., 2000; Lu et al., 2002; Jones et al., 2004). Together with results described above, these data suggest that Arg and $\mathrm{Abl}$ act in both growth cones and along processes to regulate axon and dendrite branching.

\section{Arg is required for integrin-mediated stimulation of neurite growth and branching}

We wanted to understand which specific cell surface receptors might interface with Arg signaling pathways to regulate axon and dendrite branching. Abl is activated in fibroblasts during cell adhesion to fibronectin (Lewis et al., 1996; Woodring et al., 2001). Arg is also activated by adhesion in both fibroblasts and neurons (Hernandez et al., 2004a). We therefore examined whether Arg regulates adhesion-dependent changes in neurite branching.

Adhesive cues promote dramatic changes in neurite structure within $24 \mathrm{~h}$ in culture (Lander et al., 1985; Beggs et al., 1994; Ignelzi et al., 1994). We plated wild-type and $\mathrm{arg}^{-/-}$neurons on different adhesive substrates and measured the effects on neurite structure $1 \mathrm{~d}$ later. At this stage, all neurites stain positively for MAP2. Wild-type cortical neurons form significantly more complex neurite arbors when cultured on the extracellular matrix protein laminin than when cultured on a nonspecific adhesive

cortical neurons plated on ornithine (orni), laminin (lamin), or Netrin-1 (netrin) at the indicated concentrations. Neurons were fixed at $24 \mathrm{~h}$. One experiment was performed for each condition. Wild-type neurons on ornithine, $n=20$ neurons; wild type on laminin, $n=22$ neurons; wild type on $5 \mu \mathrm{g} / \mathrm{ml}$ netrin, $n=25$ neurons; wild type on $10 \mu \mathrm{g} / \mathrm{ml}$ netrin, $n=24$ neurons; $\arg ^{-/-}$neurons on ornithine, $n=24$ neurons; $\arg ^{-/-}$on laminin, $n=19$ neurons; arg $^{-1-}$ on $5 \mu \mathrm{g} / \mathrm{ml}$ netrin, $n=24$ neurons; $\arg ^{-/-}$on $10 \mu \mathrm{g} / \mathrm{ml}$ netrin, $n=27$ neurons. ANOVA between all plating conditions is as follows: branchpoints, $p<0.0001$, length, $p<0.0001$; post hoc Student-Newman-Keuls test for each condition versus wild type plated on ornithine, ${ }^{*} p<0.05$. ANOVA between all plating conditions for each genotype: wild-type branchpoints, $p=0<0.0001 ; \mathrm{arg}^{-/-}$branchpoints, $p=0.772$; wild-type length, $p<0.0001 ; \mathrm{arg}^{-/-}$ length, $p=0.257$ 

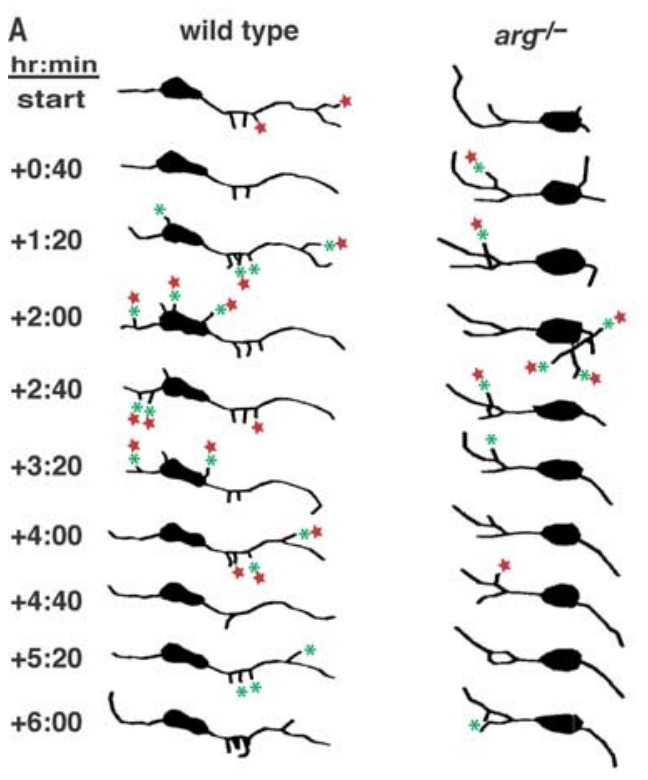
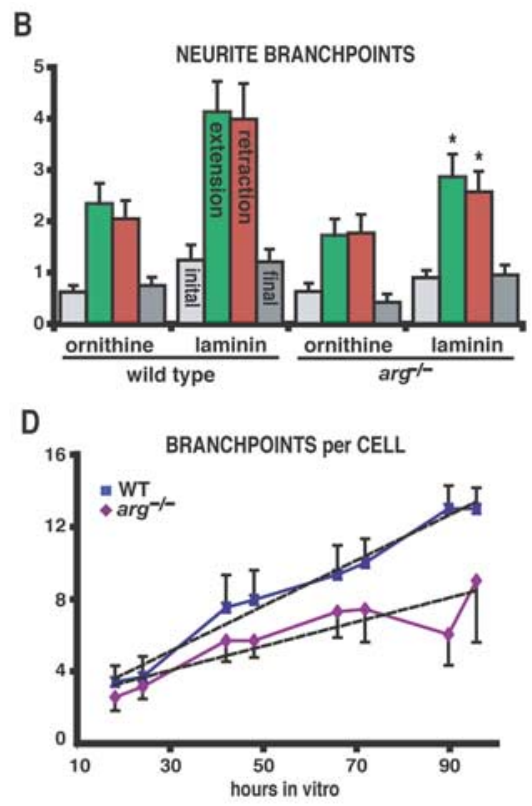

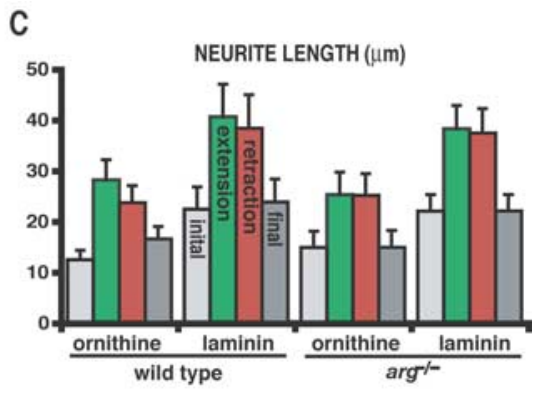

E

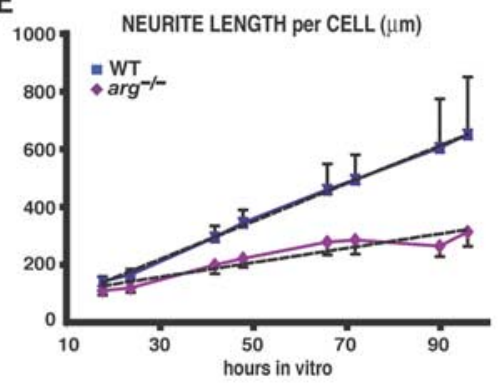

Figure 8. $\arg ^{-1-}$ neurites have reduced dynamics and accumulate branches slower than wild-type neurites. $\boldsymbol{A}$, Camera lucida drawings of representative arg ${ }^{-} /-$and wild-type neurons cultured on laminin-1-coated glass and imaged at 40 min intervals for $6 \mathrm{~h}$ at 1 DIV. Imaging times are indicated on the left. Branches that have been retracted before the subsequent imaging time are indicated with a red star. Branches that have been added since the previous imaging time are indicated with a green asterisk. Note that more stars and asterisks are associated with wild-type neurites than $\mathrm{arg}^{-1-}$ neurites, indicating that their behavior is more dynamic than arg $^{-1-}$ neurites. B, C, Quantitation of dynamic behavior of wild-type and arg ${ }^{-1-}$ neurites cultured on either polyornithine (ornithine) or polyornithine plus laminin-1 (laminin). Gray bars indicate the initial or final average number of branchpoints per neurite $(\boldsymbol{B})$ or average neurite length $(\boldsymbol{C})$ at the start of the imaging session. Green and red bars indicate the average cumulative number of branchpoints per neurite added or retracted $(\boldsymbol{B})$ or cumulative neurite length extended or retracted $(\boldsymbol{C})$ over the initial amount for the 6 h imaging session. Wild type on ornithine, $n=10$ cells, 47 neurites; wild type on laminin, $n=15$ cells, 63 neurites; arg ${ }^{-\prime-}$ on ornithine, $n=9$ cells, 43 neurites; arg ${ }^{-} /-$ on laminin, $n=14$ cells, 58 neurites. $p$ values represent statistical significance by Student's $t$ test of the difference between wild-type and arg ${ }^{-I-}$ neurons cultured on laminin, ${ }^{*} p=0.08$. $\boldsymbol{D}, \boldsymbol{E}$, Wild-type $(n=14)$ or arg $^{-1-}(n=12)$ neurons cultured on laminin-1 were imaged at 7 and $17 \mathrm{~h}$ intervals from 18 to $96 \mathrm{~h}$ in vitro ( $\left.1-4 \mathrm{DIV}\right)$. The average number of branchpoints per cell (D) or total neurite length per cell $(\boldsymbol{E})$ is plotted versus time in culture. Dashed lines are best-fit linear trendlines showing the decreased growth rate of arg $^{-1-}$ neurite arbors.

substrate, ornithine. Wild-type neurons cultured for $24 \mathrm{~h}$ on laminin exhibit a 2.25-fold increase in neurite branchpoints and a 1.19-fold increase in total neurite length over that observed in neurons cultured on ornithine (Fig. $7 A, B$ ).

Cortical neurons express several receptors for laminin, including integrins $\alpha 3 \beta 1, \alpha 4 \beta 1, \alpha 6 \beta 1$, and $\alpha 7 \beta 1$ (Schmid and Anton, 2003). The laminin-induced increases in neurite branching and elongation are eliminated by treatment of wild-type neurons with the integrin $\beta 1 / \beta 3$ inhibitor echistatin (Fig. $7 C, D$ ) (Anderson and Ferreira, 2004; Hama et al., 2004). This observation strongly suggests that the binding of neuronal integrin receptors to laminin is responsible for the increase in neurite elongation and branching observed in wild-type neurons.

Although they develop neurite arbors as well as wild-type neurons when cultured on ornithine, $\mathrm{arg}^{-/-}$neurons do not form increased numbers of neurite branches when cultured on laminin (Fig. 7A,B). Treatment of wild-type neurons with the Abl/Arg kinase inhibitor STI571 similarly reduces their neurite branching response to laminin (Fig. 7C,D). Moreover, $\mathrm{arg}^{-/-}$neurons cultured on laminin are resistant to the inhibitory effects of echistatin on neurite branching (Fig. 7C,D). Together, these data indicate that Arg is required for integrin-stimulated elaboration of neurites from cortical neurons.

\section{Integrin-mediated adhesion promotes increased neurite branch dynamics}

Axon and dendrite branching are highly dynamic processes. New axon branches emerge as F-actin-rich filopodia (Bastmeyer and O'Leary, 1996), which evolve into growth cones after microtubule invasion (Dent and Kalil, 2001) (for review, see Luo, 2002).
Dendrite branches in developing arbors extend and retract rapidly, such that many more trial branches are formed and retracted than finally exist in the mature arbor (Dailey and Smith, 1996; Wu et al., 1999; Wong et al., 2000). Artificially slowing the dynamics of dendrite branch extension and retraction also slows the overall rate of arbor growth (Wu and Cline, 1998; Wong et al., 2000), indicating that branch dynamics determine the rate and extent of dendrite arbor growth.

We investigated how integrin-mediated adhesion affects the dynamic behavior of neurite branches in wild-type and $\mathrm{arg}^{-1-}$ neurite arbors. Cortical neurons were cultured on ornithine or laminin for $\sim 18 \mathrm{~h}$ in vitro before beginning timelapse imaging for $6 \mathrm{~h}$ at 40 min intervals. arg $^{-1-}$ neurons cultured on ornithine exhibited 26\% fewer branchpoint additions and 13\% fewer branchpoint retractions over the $6 \mathrm{~h}$ imaging period than wildtype neurons on ornithine (Fig. $8 B$ ). Culturing wild-type neurons on laminin increased rates of neurite branchpoint addition and retraction by nearly twofold over rates observed on ornithine. In contrast, although $\arg ^{-1-}$ neurons exhibited modest increases in the rates of branchpoint addition and retraction when cultured on laminin, rates of branch addition and retraction were 31 and $36 \%$ lower than in wild-type neurons, respectively (Fig. $8 A, B$ ). The rates of neurite length extension and retraction were stimulated by laminin similarly in wild-type and $\mathrm{arg}^{-1-}$ neurons, indicating that once a branchpoint has formed, extension of the resulting neurite occurs normally in $\mathrm{arg}^{-1-}$ neurons (Fig. 8C). Together, these experiments demonstrate that $\mathrm{arg}^{-1-}$ neurites are less dynamic than wild-type neurites and less responsive to stimulation by integrin-mediated adhesion.

To understand how the reduced branch dynamics of $\mathrm{arg}^{-1-}$ 
neurites affects overall neurite arbor growth, we imaged neurons cultured on laminin at 7 and $17 \mathrm{~h}$ intervals for $3 \mathrm{~d}$ in vitro (from 1 to 4 DIV) (Fig. $8 D, E$ ). Wild-type neurons accumulated branchpoints at a rate of 0.13 branchpoints/h and increased in total neurite length at $6.7 \mu \mathrm{m} / \mathrm{h}$ (rates from linear trendline fit to data in Fig. $8 D, E$ ). Compared with wild-type neurites, rates of growth of $\mathrm{arg}^{-1-}$ neurites were reduced by half, with 0.07 branchpoints added per hour and total neurite length increasing $2.5 \mu \mathrm{m} / \mathrm{h}$. These data support the hypothesis that the reduced integrinmediated branch dynamics of $\mathrm{arg}^{-1-}$ neurites leads to slower arbor growth resulting from reduced rates of branch accumulation over several days.

\section{Arg is required for integrin-mediated responses to Semaphorin 7A}

Laminin-1 expression in the mouse brain is high before birth but is downregulated postnatally (Liesi, 1985) before dendrites undergo their most rapid growth. This observation suggests that other cues activate integrins to regulate dendrite development in the postnatal brain. Recent studies have shown that integrins can serve as receptors for the axon guidance molecules Netrin-1 (Yebra et al., 2003) and Semaphorin 7A (Pasterkamp et al., 2003).

We tested whether integrin-dependent neurite branching can be stimulated by adhesion to Netrin-1 or Sema7A in wild-type neurons. Culturing neurons on Netrin-1 had no effect on neurite branching in either wild-type or $\mathrm{arg}^{-/-}$neurons (Fig. 7G) but led to a similar inhibition of neurite elongation in wild-type and $\mathrm{arg}^{-1-}$ neurons compared with neurons plated on ornithine (Fig. $7 H$ ). These data indicate that Netrin-1 does not stimulate neurite branching in either wild-type or $\mathrm{arg}^{-/-}$cortical neurons.

Wild-type neurons cultured on coverslips coated with an APtagged human Sema7A fusion protein exhibited a dosedependent increase in neurite elongation and branching relative to neurons cultured on AP alone (Fig. 7 E, F). Sema7A stimulated neurite elongation and branching slightly in $\mathrm{arg}^{-1-}$ neurons, but this increase was greatly reduced compared with wild-type responses. Importantly, treatment of wild-type neurons with STI571 attenuated their branching response to Sema7A, but $\mathrm{arg}^{-1-}$ neuron responses were resistant to STI571 treatment. These results indicate that the full Sema7A-stimulated increase in neurite branching requires Arg.

Treatment of wild-type neurons with echistatin eliminated their response to Sema7A, strongly suggesting that increases in neurite length and branching result from the binding of Sema7A to integrin receptors (Fig. 7E,F). Treatment of $\mathrm{arg}^{-/-}$neurons with echistatin also blocked their slight increase in elongation and branching (Fig. $7 E, F$ ). Together, these results indicate that Arg is required for the maximal neurite branching response to Sema7A and suggest that other downstream-signaling pathways may also contribute to the Sema7A neurite-branching response.

\section{Discussion}

We report that $\mathrm{Abl}$ and Arg function after dendrite development to mediate signals from adhesive cues that are critical for dendrite maintenance. Dendrite arbors are normal in $\mathrm{arg}^{-/-}$and bs-dko cortical neurons at $\mathrm{P} 21$ but become reduced in size and complexity by 6 weeks resulting from increased loss of dendrite branches relative to wild-type neurons. Arg overexpression in primary cortical neurons promotes increased axon and dendrite branching. $\mathrm{Abl}$ and Arg are required for integrin-dependent stimulation of neurite branch dynamics by laminin or Sema7A, leading to increased arbor growth rate. Our results suggest that dendrite maintenance can be distinguished from dendrite development both temporally and by their differential requirements for specific molecular components.

Where do Abl and Arg act to regulate dendrite maintenance? Previous studies have shown that Abl can promote neurite branching and elongation in culture (Zukerberg et al., 2000; Woodring et al., 2002; Jones et al., 2004). We show that Abl and Arg localize to both axons and dendrites, and that Arg promotes axon and dendrite branching in cultured cortical neurons. These data suggest that $\mathrm{Abl}$ and Arg may control dendrite morphogenesis directly by acting in the dendrite to regulate its dynamic behavior or indirectly by regulating the formation and targeting of axons that innervate these dendrites.

Several observations suggest that $\mathrm{Abl}$ and Arg act directly in cortical dendrites to regulate dendrite maintenance in vivo. First, examination of the two major axon tracts innervating the cortex, the internal capsule and corpus callosum, indicate that they are normal in $\mathrm{arg}^{-/-}$and bs-dko mice. Second, dye-tracing studies demonstrate that the corticocortical afferents distribute normally, with preferential targeting of the deeper cortical layers. Previous work indicates that callosal axons innervating the contralateral cortical hemisphere are not restricted to form synapses on either apical or basal dendrite arbors (Elberger, 1994a,b). Therefore, dendritic reductions resulting from defects in axonal targeting should occur in both apical and basal dendrites. The finding that $\mathrm{abl}^{-/-}$and $\mathrm{arg}^{-/-}$neurons have reductions only in their basal trees argues that afferent axon mistargeting cannot explain the dendritic defects in these mice. It remains possible that mice lacking Abl and/or Arg exhibit subtle defects in callosal axon branching and targeting that are below the resolution of our analysis. By causing a failure to innervate proper dendrite targets, such axonal defects could contribute to a reduction in dendrite branch maintenance.

\section{Integrin signaling through $\mathrm{Abl}$ and Arg modulates dendrite structure}

Adhesive interactions with the ECM have been shown to participate in the regulation of dendrite development in vivo. For example, dendrite complexity is dramatically reduced in the hippocampus of reeler mutant mice lacking the ECM glycoprotein Reelin (Niu et al., 2004). In vitro, adhesion receptor ligands such as laminin-1 and L1 are well characterized stimulators of neurite outgrowth in multiple types of cultured neurons (Reichardt and Tomaselli, 1991; Kiryushko et al., 2004).

Expression of different integrin receptor $\alpha$ and $\beta$ subunits is widespread in the brain (Cousin et al., 1997; Pinkstaff et al., 1998, 1999; Bi et al., 2001; Schmid and Anton, 2003). The binding of distinct neuronal integrin receptors to ECM proteins (e.g., laminin, fibronectin, etc.) can potently stimulate neurite outgrowth in vitro (Reichardt and Tomaselli, 1991), suggesting that integrins can regulate axon and dendrite morphogenesis in vivo. We showed that Arg is required for neurite branching stimulated by integrin-dependent adhesion to laminin-1. However, because its expression is downregulated postnatally, it is unlikely that laminin-1 is the ligand activating integrins in neurons of the mature brain.

The axon guidance molecules Netrin-1 (Yebra et al., 2003) and Sema7A (Pasterkamp et al., 2003) can act as integrin receptor ligands. A growing number of studies have demonstrated that axon guidance cues can also guide dendrite growth (Jan and Jan, 2003; Kim and Chiba, 2004). These findings suggest that Netrin-1 and Sema7A could serve as integrin ligands regulating dendrite structure. In fact, we found that Sema7A promotes neurite 
branching and elongation from wild type neurons and that this response is diminished in $\mathrm{arg}^{-1-}$ neurons or in wild type neurons treated with the Abl/Arg kinase inhibitor STI571. Interestingly, Sema7A is expressed throughout the cortex during postnatal periods, although cortical dendrite morphology has not been examined in Sema7A knock-out mice (J. Pasterkamp and A. Kolodkin, personal communication). We propose that Sema7A or possibly related cues activate integrin receptors to promote dendrite maintenance through Abl and Arg in mature neurons. To this end, Semaphorin $3 \mathrm{~A}$ is required for the elaboration of dendrite branches in cortical pyramidal neurons (Fenstermaker et al., 2004).

\section{Regulation of branch dynamics by Abl and Arg: a role in dendrite maintenance in vivo?}

Several reports have shown that immature neurons undergoing extensive arbor growth have high rates of branch extension and retraction that gradually decline as neurons reach maturity $(\mathrm{Wu}$ et al., 1999; Trachtenberg et al., 2002; Mizrahi and Katz, 2003). It is generally believed that this dynamic behavior allows immature neurons to remodel rapidly in response to developmental cues, but that mature neurons have more stable dendritic structures. However, few studies have investigated dendrite branch dynamics in more mature mammalian neurons in vivo over time intervals sufficient to detect branch dynamics in young animals (i.e., intervals of 20-60 min). Moreover, investigations of cortical dendrite dynamics have focused on apical tufts (Grutzendler et al., 2002; Trachtenberg et al., 2002); no studies have monitored basal dendrite dynamics, in which developmental defects are often reported. Therefore, the existence of continued dendrite dynamics in more mature neurons cannot be ruled out.

In fact, several studies demonstrate that mature neurons can remodel in response to various stimuli. For example, neuronal activity induced by bicuculline treatment increases dendrite branch dynamics of mitral and tufted cells in the adult olfactory bulb (Mizrahi and Katz, 2003). The dendrites of mature cortical neurons are capable of dramatic remodeling and growth in response to the neurotrophin BDNF (McAllister et al., 1995, 1997). Importantly, BDNF stimulates dendritic growth from established P28 ferret cortical neurons by increasing rates of branch dynamics (Horch et al., 1999; Horch and Katz, 2002). Furthermore, loss of BDNF signaling through TrkB (tyrosine receptor kinase B) receptors results in cortical dendrite arbor shrinkage after $\mathrm{P} 3(\mathrm{Xu}$ et al., 2000; Gorski et al., 2003). These studies hint that low-level remodeling of dendrite branches may occur in cortical dendrites, and this remodeling may be required for arbor size maintenance after postnatal week 3. Like BDNF, Abl and Arg are required for dendrite maintenance after P21. Our data demonstrate that Arg is required for adhesion-dependent stimulation of neurite branch dynamics that promote arbor elaboration. We speculate that Abl and Arg may influence dendrite maintenance after P21 by modulating dendrite dynamics in response to adhesive cues (supplemental Fig. 5, available at www.jneurosci.org as supplemental material). Although technically challenging, timelapse imaging of basal dendrite arbors in the intact mouse brain will be necessary to ultimately determine whether Abl and Arg regulate branch dynamics in mature neurons and whether dendrite arbor maintenance requires this dynamic behavior.

We observed that $\mathrm{arg}^{-/-}$neurons isolated from embryonic mice have intrinsically reduced dynamic behavior on adhesive surfaces relative to wild-type neurons. It is not clear why defects in dendrite morphogenesis become evident only relatively late in development in the intact brain, especially because Arg protein levels remain relatively stable from embryonic through postnatal development. One possibility is that expression of the cue(s) that activate Arg is temporally restricted to late postnatal development. It is also possible that redundant signaling pathways may supplement reduced Arg activity allowing for normal development through P21 in the $\arg ^{-1-}$ mice.

\section{Possible downstream targets of Abl and Arg in regulation of axon/dendrite branching}

Arg requires its kinase activity to promote neurite branching either when overexpressed or activated by adhesion to laminin-1 or Sema7A in cultured neurons. Thus, Arg likely promotes dendrite branching by phosphorylating one or more cytoskeletal regulatory proteins. One candidate is p190RhoGAP, a substrate of Arg during postnatal mouse brain development (supplemental Fig. 5, available at www.jneurosci.org as supplemental material) (Hernandez et al., 2004a). p190RhoGAP is an antagonist of the RhoA (Rho) GTPase, which negatively regulates dendrite branch formation in several model systems (Ruchhoeft et al., 1999) (Nakayama et al., 2000; Wong et al., 2000). Arg mediates phosphorylation and activation of p190RhoGAP in neurons after adhesion to laminin-1 (Hernandez et al., 2004a), suggesting that Arg functions to counteract Rho in response to adhesive cues. Abl inhibits Rho activity in cultured hippocampal neurons, because Abl inhibition using STI571 leads to increased Rho activity (Jones et al., 2004), consistent with the idea that Abl kinases phosphorylate and activate p190RhoGAP. Several other substrates of Abl and Arg are also expressed in the brain, including paxillin (Turner, 1991; Mazaki et al., 1998), Sos1 (Guerrero et al., 1996; Esteban et al., 2000), and Crk (Ogawa et al., 1994; Kharbanda et al., 1995), but it is unclear whether these proteins contribute to regulation of axon or dendrite morphogenesis in vivo.

Genetic studies in Drosophila indicate that Abl regulates axon guidance through interactions with $\mathrm{F}$-actin and microtubules (Wills et al., 1999a). Splaying of microtubule bundles at axon branch sites is followed by localized actin polymerization and the emergence of an F-actin-rich protrusion that evolves into a new growth cone (Bastmeyer and O'Leary, 1996; Dent et al., 1999; Dent and Kalil, 2001). In fibroblasts, Arg requires F-actin- and microtubule-binding domains located in its C-terminal half to promote adhesion-dependent protrusions at the periphery (Wang et al., 2001; Miller et al., 2004). Although an Arg mutant lacking F-actin and microtubule-binding domains promotes neurite branching when overexpressed in culture, Arg may use these domains to coordinate F-actin and microtubule rearrangements at branch sites in vivo.

\section{Does misregulation of Abl family kinases contribute to neurological disorders?}

Dendritic defects are the most consistent anatomical correlates of mental retardation syndromes (Kaufmann and Moser, 2000) and are also observed in the prefrontal cortex of schizophrenia patients (Glantz and Lewis, 2000; Broadbelt et al., 2002). Identification of the genetic lesions in several nonsyndromic mental retardation cases highlights the importance of cytoskeletal regulation by the Rho GTPases in controlling dendrite structure (Ramakers, 2000). Dysfunctional Abl and Arg signaling may contribute to the pathophysiology of some human mental retardation syndromes or psychiatric diseases by perturbing Rho signaling and other cytoskeletal regulatory pathways that maintain dendrite arbors. 


\section{References}

Anderson KL, Ferreira A (2004) alphal integrin activation: a link between beta-amyloid deposition and neuronal death in aging hippocampal neurons. J Neurosci Res 75:688-697.

Bashaw GJ, Kidd T, Murray D, Pawson T, Goodman CS (2000) Repulsive axon guidance: abelson and enabled play opposing roles downstream of the roundabout receptor. Cell 101:703-715.

Bastmeyer M, O'Leary DD (1996) Dynamics of target recognition by interstitial axon branching along developing cortical axons. J Neurosci 16:1450-1459.

Beggs HE, Soriano P, Maness PF (1994) NCAM-dependent neurite outgrowth is inhibited in neurons from Fyn-minus mice. J Cell Biol 127:825-833.

Bi X, Lynch G, Zhou J, Gall CM (2001) Polarized distribution of alpha5 integrin in dendrites of hippocampal and cortical neurons. J Comp Neurol 435:184-193.

Broadbelt K, Byne W, Jones LB (2002) Evidence for a decrease in basilar dendrites of pyramidal cells in schizophrenic medial prefrontal cortex. Schizophr Res 58:75-81.

Cousin B, Leloup C, Penicaud L, Price J (1997) Developmental changes in integrin beta-subunits in rat cerebral cortex. Neurosci Lett 234:161-165.

Dailey ME, Smith SJ (1996) The dynamics of dendritic structure in developing hippocampal slices. J Neurosci 16:2983-2994.

Dent EW, Kalil K (2001) Axon branching requires interactions between dynamic microtubules and actin filaments. J Neurosci 21:9757-9769.

Dent EW, Callaway JL, Szebenyi G, Baas PW, Kalil K (1999) Reorganization and movement of microtubules in axonal growth cones and developing interstitial branches. J Neurosci 19:8894-8908.

Elberger AJ (1994a) Transitory corpus callosum axons projecting throughout developing rat visual cortex revealed by Dil. Cereb Cortex 4:279-299.

Elberger AJ (1994b) The corpus callosum provides a massive transitory input to the visual cortex of cat and rat during early postnatal development. Behav Brain Res 64:15-33.

Elkins T, Zinn K, McAllister L, Hoffmann FM, Goodman CS (1990) Genetic analysis of a Drosophila neural cell adhesion molecule: interaction of fasciclin I and Abelson tyrosine kinase mutations. Cell 60:565-575.

Esteban LM, Fernandez-Medarde A, Lopez E, Yienger K, Guerrero C, Ward JM, Tessarollo L, Santos E (2000) Ras-guanine nucleotide exchange factor sos2 is dispensable for mouse growth and development. Mol Cell Biol 20:6410-6413.

Fenstermaker V, Chen Y, Ghosh A, Yuste R (2004) Regulation of dendritic length and branching by semaphorin 3A. J Neurobiol 58:403-412.

Gertler FB, Bennett RL, Clark MJ, Hoffmann FM (1989) Drosophila abl tyrosine kinase in embryonic CNS axons: a role in axonogenesis is revealed through dosage-sensitive interactions with disabled. Cell 58:103-113.

Gibb R, Kolb B (1998) A method for vibratome sectioning of Golgi-Cox stained whole rat brain. J Neurosci Methods 79:1-4.

Giniger E (1998) A role for Abl in Notch signaling. Neuron 20:667-681.

Glantz LA, Lewis DA (2000) Decreased dendritic spine density on prefrontal cortical pyramidal neurons in schizophrenia. Arch Gen Psychiatry 57:65-73.

Gorski JA, Zeiler SR, Tamowski S, Jones KR (2003) Brain-derived neurotrophic factor is required for the maintenance of cortical dendrites. J Neurosci 23:6856-6865.

Grutzendler J, Kasthuri N, Gan WB (2002) Long-term dendritic spine stability in the adult cortex. Nature 420:812-816.

Guerrero C, Rojas JM, Chedid M, Esteban LM, Zimonjic DB, Popescu NC, Font de Mora J, Santos E (1996) Expression of alternative forms of Ras exchange factors GRF and SOS1 in different human tissues and cell lines. Oncogene 12:1097-1107.

Hama H, Hara C, Yamaguchi K, Miyawaki A (2004) PKC signaling mediates global enhancement of excitatory synaptogenesis in neurons triggered by local contact with astrocytes. Neuron 41:405-415.

Hernandez SE, Settleman J, Koleske AJ (2004a) Adhesion-dependent regulation of p190RhoGAP in the developing brain by the Abl-related gene tyrosine kinase. Curr Biol 14:691-696.

Hernandez SE, Krishnaswami M, Miller AL, Koleske AJ (2004b) How do Abl family kinases regulate cell shape and movement? Trends Cell Biol 14:36-44.

Horch HW, Katz LC (2002) BDNF release from single cells elicits local dendritic growth in nearby neurons. Nat Neurosci 5:1177-1184.
Horch HW, Kruttgen A, Portbury SD, Katz LC (1999) Destabilization of cortical dendrites and spines by BDNF. Neuron 23:353-364.

Huttenlocher PR (1974) Dendritic development in neocortex of children with mental defect and infantile spasms. Neurology 24:203-210.

Ignelzi Jr MA, Miller DR, Soriano P, Maness PF (1994) Impaired neurite outgrowth of src-minus cerebellar neurons on the cell adhesion molecule L1. Neuron 12:873-884.

Innocenti GM (1986) General organization of callosal connections in the cerebral cortex. In: Cerebral cortex, Vol 5, Sensory-motor areas and aspects of connectivity (Jones EG, Peters A, eds), pp 291-353. New York: Plenum.

Isaka F, Ishibashi M, Taki W, Hashimoto N, Nakanishi S, Kageyama R (1999) Ectopic expression of the bHLH gene Math1 disturbs neural development. Eur J Neurosci 11:2582-2588.

Jan YN, Jan LY (2003) The control of dendrite development. Neuron $40: 229-242$.

Jones LB (2004) Loss of spines and neuropil. Int Rev Neurobiol 59:1-18.

Jones SB, Lu HY, Lu Q (2004) Abl tyrosine kinase promotes dendrogenesis by inducing actin cytoskeletal rearrangements in cooperation with rho family small GTPases in hippocampal neurons. J Neurosci 24:8510-8521.

Kaufmann WE, Moser HW (2000) Dendritic anomalies in disorders associated with mental retardation. Cereb Cortex 10:981-991.

Kharbanda S, Ren R, Pandey P, Shafman TD, Feller SM, Weichselbaum RR, Kufe DW (1995) Activation of the c-Abl tyrosine kinase in the stress response to DNA-damaging agents. Nature 376:785-788.

Kim S, Chiba A (2004) Dendritic guidance. Trends Neurosci 27:194-202.

Kiryushko D, Berezin V, Bock E (2004) Regulators of neurite outgrowth: role of cell adhesion molecules. Ann NY Acad Sci 1014:140-154.

Koleske AJ, Gifford AM, Scott ML, Nee M, Bronson RT, Miczek KA, Baltimore D (1998) Essential roles for the Abl and Arg tyrosine kinases in neurulation. Neuron 21:1259-1272.

Lander AD, Fujii DK, Reichardt LF (1985) Laminin is associated with the "neurite outgrowth-promoting factors" found in conditioned media. Proc Natl Acad Sci USA 82:2183-2187.

Lewis JM, Baskaran R, Taagepera S, Schwartz MA, Wang JY (1996) Integrin regulation of c-Abl tyrosine kinase activity and cytoplasmic-nuclear transport. Proc Natl Acad Sci USA 93:15174-15179.

Li E, Bestor TH, Jaenisch R (1992) Targeted mutation of the DNA methyltransferase gene results in embryonic lethality. Cell 69:915-926.

Liesi P (1985) Do neurons in the vertebrate CNS migrate on laminin? EMBO J 4:1163-1170.

Lohmann C, Myhr KL, Wong RO (2002) Transmitter-evoked local calcium release stabilizes developing dendrites. Nature 418:177-181.

Lu Q, Mukhopadhyay NK, Griffin JD, Paredes M, Medina M, Kosik KS (2002) Brain armadillo protein delta-catenin interacts with Abl tyrosine kinase and modulates cellular morphogenesis in response to growth factors. J Neurosci Res 67:618-624.

Luo L (2002) Actin cytoskeleton regulation in neuronal morphogenesis and structural plasticity. Annu Rev Cell Dev Biol 18:601-635.

Mazaki Y, Uchida H, Hino O, Hashimoto S, Sabe H (1998) Paxillin isoforms in mouse. Lack of the gamma isoform and developmentally specific beta isoform expression. J Biol Chem 273:22435-22441.

McAllister AK (2000) Cellular and molecular mechanisms of dendrite growth. Cereb Cortex 10:963-973.

McAllister AK, Lo DC, Katz LC (1995) Neurotrophins regulate dendritic growth in developing visual cortex. Neuron 15:791-803.

McAllister AK, Katz LC, Lo DC (1997) Opposing roles for endogenous BDNF and NT-3 in regulating cortical dendritic growth. Neuron 18:767-778.

McWhirter JR, Wang JY (1993) An actin-binding function contributes to transformation by the Bcr-Abl oncoprotein of Philadelphia chromosome-positive human leukemias. EMBO J 12:1533-1546.

Miller AL, Wang Y, Mooseker MS, Koleske AJ (2004) The Abl-related gene (Arg) requires its F-actin-microtubule cross-linking activity to regulate lamellipodial dynamics during fibroblast adhesion. J Cell Biol 165:407-419.

Miller B, Chou L, Finlay BL (1993) The early development of thalamocortical and corticothalamic projections. J Comp Neurol 335:16-41.

Miller MW (1988) Development of projection and local circuit neurons in the neocortex. In: Cerebral cortex (Jones AP, ed), pp 133-175. New York: Plenum. 
Mizrahi A, Katz LC (2003) Dendritic stability in the adult olfactory bulb. Nat Neurosci 6:1201-1207.

Moresco EM, Koleske AJ (2003) Regulation of neuronal morphogenesis and synaptic function by Abl family kinases. Curr Opin Neurobiol 13:535-544.

Moresco EM, Scheetz AJ, Bornmann WG, Koleske AJ, Fitzsimonds RM (2003) Abl family nonreceptor tyrosine kinases modulate short-term synaptic plasticity. J Neurophysiol 89:1678-1687.

Naegele JR, Jhaveri S, Schneider GE (1988) Sharpening of topographical projections and maturation of geniculocortical axon arbors in the hamster. J Comp Neurol 277:593-607.

Nakayama AY, Harms MB, Luo L (2000) Small GTPases Rac and Rho in the maintenance of dendritic spines and branches in hippocampal pyramidal neurons. J Neurosci 20:5329-5338.

Niu S, Renfro A, Quattrocchi CC, Sheldon M, D’Arcangelo G (2004) Reelin promotes hippocampal dendrite development through the VLDLR/ ApoER2-Dab1 pathway. Neuron 41:71-84.

Ogawa S, Toyoshima H, Kozutsumi H, Hagiwara K, Sakai R, Tanaka T, Hirano N, Mano H, Yazaki Y, Hirai H (1994) The C-terminal SH3 domain of the mouse c-Crk protein negatively regulates tyrosinephosphorylation of Crk associated p130 in rat 3Y1 cells. Oncogene 9:1669-1678

Pasterkamp RJ, Peschon JJ, Spriggs MK, Kolodkin AL (2003) Semaphorin 7A promotes axon outgrowth through integrins and MAPKs. Nature 424:398-405.

Pinkstaff JK, Lynch G, Gall CM (1998) Localization and seizure-regulation of integrin beta $1 \mathrm{mRNA}$ in adult rat brain. Brain Res Mol Brain Res 55:265-276.

Pinkstaff JK, Detterich J, Lynch G, Gall C (1999) Integrin subunit gene expression is regionally differentiated in adult brain. J Neurosci 19:1541-1556.

Purpura DP (1975) Normal and aberrant neuronal development in the cerebral cortex of human fetus and young infant. UCLA Forum Med Sci $18: 141-169$.

Ramakers GJ (2000) Rho proteins and the cellular mechanisms of mental retardation. Am J Med Genet 94:367-371.

Redmond L, Kashani AH, Ghosh A (2002) Calcium regulation of dendritic growth via CaM kinase IV and CREB-mediated transcription. Neuron 34:999-1010

Reichardt LF, Tomaselli KJ (1991) Extracellular matrix molecules and their receptors: functions in neural development. Annu Rev Neurosci 14:531-570.

Ruchhoeft ML, Ohnuma S, McNeill L, Holt CE, Harris WA (1999) The neuronal architecture of Xenopus retinal ganglion cells is sculpted by rhofamily GTPases in vivo. J Neurosci 19:8454-8463.

Schmid RS, Anton ES (2003) Role of integrins in the development of the cerebral cortex. Cereb Cortex 13:219-224.

Sini P, Cannas A, Koleske AJ, Di Fiore PP, Scita G (2004) Abl-dependent tyrosine phosphorylation of Sos-1 mediates growth-factor-induced Rac activation. Nat Cell Biol 6:268-274.

Szebenyi G, Callaway JL, Dent EW, Kalil K (1998) Interstitial branches develop from active regions of the axon demarcated by the primary growth cone during pausing behaviors. J Neurosci 18:7930-7940.

Tanis KQ, Veach D, Duewel HS, Bornmann WG, Koleske AJ (2003) Two distinct phosphorylation pathways have additive effects on Abl family kinase activation. Mol Cell Biol 23:3884-3896.
Threadgill R, Bobb K, Ghosh A (1997) Regulation of dendritic growth and remodeling by Rho, Rac, and Cdc42. Neuron 19:625-634.

Trachtenberg JT, Chen BE, Knott GW, Feng G, Sanes JR, Welker E, Svoboda $\mathrm{K}$ (2002) Long-term in vivo imaging of experience-dependent synaptic plasticity in adult cortex. Nature 420:788-794.

Turner CE (1991) Paxillin is a major phosphotyrosine-containing protein during embryonic development. J Cell Biol 115:201-207.

Vaillant AR, Zanassi P, Walsh GS, Aumont A, Alonso A, Miller FD (2002) Signaling mechanisms underlying reversible, activity-dependent dendrite formation. Neuron 34:985-998.

Van Etten RA, Jackson PK, Baltimore D, Sanders MC, Matsudaira PT, Janmey PA (1994) The COOH terminus of the c-Abl tyrosine kinase contains distinct F- and G-actin binding domains with bundling activity. J Cell Biol 124:325-340.

Wang Y, Miller AL, Mooseker MS, Koleske AJ (2001) The Abl-related gene (Arg) nonreceptor tyrosine kinase uses two F-actin-binding domains to bundle F-actin. Proc Natl Acad Sci USA 98:14865-14870.

Whitford KL, Dijkhuizen P, Polleux F, Ghosh A (2002) Molecular control of cortical dendrite development. Annu Rev Neurosci 25:127-149.

Wills Z, Marr L, Zinn K, Goodman CS, Van Vactor D (1999a) Profilin and the Abl tyrosine kinase are required for motor axon outgrowth in the Drosophila embryo. Neuron 22:291-299.

Wills Z, Bateman J, Korey CA, Comer A, Van Vactor D (1999b) The tyrosine kinase $\mathrm{Abl}$ and its substrate enabled collaborate with the receptor phosphatase Dlar to control motor axon guidance. Neuron 22:301-312.

Wong WT, Faulkner-Jones BE, Sanes JR, Wong RO (2000) Rapid dendritic remodeling in the developing retina: dependence on neurotransmission and reciprocal regulation by Rac and Rho. J Neurosci 20:5024-5036.

Woodring PJ, Hunter T, Wang JY (2001) Inhibition of c-Abl tyrosine kinase activity by filamentous actin. J Biol Chem 276:27104-27110.

Woodring PJ, Litwack ED, O'Leary DD, Lucero GR, Wang JY, Hunter T (2002) Modulation of the F-actin cytoskeleton by c-Abl tyrosine kinase in cell spreading and neurite extension. J Cell Biol 156:879-892.

Woodring PJ, Hunter T, Wang JY (2003) Regulation of F-actin-dependent processes by the Abl family of tyrosine kinases. J Cell Sci 116:2613-2626.

Wu GY, Cline HT (1998) Stabilization of dendritic arbor structure in vivo by CaMKII. Science 279:222-226.

Wu GY, Zou DJ, Rajan I, Cline H (1999) Dendritic dynamics in vivo change during neuronal maturation. J Neurosci 19:4472-4483.

Xu B, Zang K, Ruff NL, Zhang YA, McConnell SK, Stryker MP, Reichardt LF (2000) Cortical degeneration in the absence of neurotrophin signaling: dendritic retraction and neuronal loss after removal of the receptor TrkB. Neuron 26:233-245.

Yebra M, Montgomery AM, Diaferia GR, Kaido T, Silletti S, Perez B, Just ML, Hildbrand S, Hurford R, Florkiewicz E, Tessier-Lavigne M, Cirulli V (2003) Recognition of the neural chemoattractant Netrin-1 by integrins alpha6beta4 and alpha3beta1 regulates epithelial cell adhesion and migration. Dev Cell 5:695-707.

Zoghbi HY (2003) Postnatal neurodevelopmental disorders: meeting at the synapse? Science 302:826-830.

Zukerberg LR, Patrick GN, Nikolic M, Humbert S, Wu CL, Lanier LM, Gertler FB, Vidal M, Van Etten RA, Tsai LH (2000) Cables links Cdk5 and c-Abl and facilitates Cdk5 tyrosine phosphorylation, kinase upregulation, and neurite outgrowth. Neuron 26:633-646. 